\title{
All-pay auctions with pre- and post-bidding options
}

\author{
Fredrik $\varnothing$ degaard \\ Western University \\ Chris K. Anderson \\ Cornell University
}

\begin{abstract}
Motivated by the emergence of online penny or pay-to-bid auctions, in this study, we analyze the operational consequences of all-pay auctions competing with fixed list price stores. In all-pay auctions, bidders place bids, and highest bidder wins. Depending on the auction format, the winner pays either the amount of their bid or that of the second-highest bid. All losing bidders forfeit their bids, regardless of the auction format. Bidders may visit the store, both before and after bidding, and buy the item at the fixed list price. In a modified version, we consider a setting where bidders can use their sunk bid as a credit towards buying the item from the auctioneer at a fixed price (different from the list price). We characterize a symmetric equilibrium in the bidding/buying strategy and derive optimal list prices for both the seller and auctioneer to maximize expected revenue. We consider two situations: (1) one firm operating both channels (i.e. fixed list price store and all-pay auction), and (2) two competing firms, each operating one of the two channels.
\end{abstract}

\section{Introduction}

Auctions are fascinating and important sales mechanisms that date back to antiquity. They have been used extensively in both business-to-consumer and business-to-business markets. With the advent of the Internet, auctions have also become popular in consumer-to-consumer markets as exemplified by the online auction behemoth eBay. In addition to the many Internet-based traditional auction formats, where a seller auctions an item to a group of buyers, the dot-com entrepreneurial spirit gave rise to many non-traditional auction formats and auction-based business solutions. Two notable examples include Priceline, a Name-Your-Own-Price 'reverse auction' mechanism, and Google's AdWords, a keyword auction for online ad space.

The latest Internet-based auction mechanism that has been growing in popularity is the penny or pay-to-bid auction, examples of which include quibids.com, dealdash.com, beezid.com, and the former online auction sites swoopo.com and offandaway.com. Three particular features separate these online auctions sites from the more common ones and, in particular, from eBay. First, unlike eBay, which hosts auctions for sellers only, the penny auction sites act as the seller of the items auctioned, which are usually brand new and are predominately from the consumer electronics category. Second, unlike the hard-ending rule of eBay, where an auction ends at a pre-specified date and time, penny auctions employ a 'going, going,... .gone' ending rule by extending the auction clock for each incoming bid in the final moments. Third, the penny auction mechanism is drastically different in that bidders first buy a pack of 'bids' for a fixed price (e.g., a pack of 100 'bids' for $\$ 60$ ), and these 'bids' are then used to nominally raise the price in an auction (e.g., by one cent - hence the name penny auction). In other words, for the given example, raising the auction price by one 
cent costs the bidder 60 cents. The bidder who places the last 'bid' wins the item and pays the final auction price, in addition to the incurred sunk cost of the 'bids' purchased at the outset of the process; all non-winning bidders incur only the sunk cost of 'bidding'. Despite their peculiar format, due to the nature of this sunk bidding cost, penny auctions can, in effect, be characterized as secondprice all-pay auctions.

All-pay auctions are similar to traditional auctions in that whoever submits the highest bid wins the item; however, unlike traditional auctions, where non-winning bidders pay nothing, in allpay auctions, non-winning bidders forfeit their bids (i.e., all bidders pay their bid but only the highest bidder wins the item). The added prefix second-price refers to the fact that the highest bidder must pay the amount of the second-highest bid only, and not the actual amount they bid. Although their process might seem a bit peculiar, all-pay auctions are well established in the auction literature. More details regarding auction theory and all-pay auctions are discussed in Section 2. To see how penny auctions constitute, in effect, second-price all-pay auctions, consider the case when there are only two bidders. With only two bidders, the first bidder who fails to counter-bid will lose and forfeit the sunk bidding cost, while the winning bidder will have matched the cost of bidding (i.e., paid the same amount as the second-highest bidder). Of course, the winner must also pay the additional final auction price, but this amount will be an order of magnitude smaller than the sunk bidding cost, and thus, can be considered potentially negligible. The extension to multiple bidders is immediate: in each "bidding round", bidders must decide whether to stay in the game by placing a bid, or decide to drop out and accept the sunk cost of bidding. There remains, however, the issue how to enforce all bidders to participate in each "bidding round". More details regarding the link between penny auctions and all-pay auctions are discussed in Section 3.

Bidders are drawn to participate in online penny auctions by the chance of winning an item at a highly discounted price. From the online penny auctioneers' perspective, the expectation is that there will be enough active bidders such that the revenue from all 'bids' exceeds the cost of the item. Typical anecdotal stories tell us that a winning bidder may acquire a brand new smartphone for just $\$ 50$, while the penny auction site collects a total revenue of $\$ 2000$ from the bidding process. These stories have generated much negative press in academia, newspapers and blogs, and critics have basically labeled penny auctions as online gambling (Robinson, Giebelhausen, \& Cotte, 2013; USA Today, 2011; NY Times, 2009a, 2009b; Guina, 2009). In an extreme example, a class-action lawsuit has been filed against quibids.com, claiming that it is more akin to a gambling website than an auction website (BusinessWire, 2010). Since online gambling is regulated in most countries, the general strategy from the penny auction sites has been to position themselves as 'entertainment shopping' channels. Due to the unusual and unintuitive format of all-pay auctions it is perhaps not surprising that penny auction websites are being labeled as online gambling sites.

The main motivation of this paper is to clarify some of the misunderstandings around penny auction sites, as well as to provide some insights regarding bidding strategies and analyze the operational consequences for sites themselves. Specifically, we consider a setting where bidders have access to two sales channels: a store that sells items at a fixed list price, and an all-pay auction. Bidders who choose to bid in the all-pay auction take into consideration that they can, either before or after bidding, buy the item directly at the fixed list price from the store. In a modified version to the all-pay auction, we consider a format where all losing bidders are given the option of using their sunk bid as a credit towards purchasing the item from the auctioneer at a fixed price (which, 
naturally, is higher than the store list price). The feature of using the sunk bid as a credit constitutes an interesting aspect of real- world penny auction sites because it provides an additional twist compared to traditional auctions. Our main research objectives involve uncovering whether, how, and for whom the added auction channel provides value, and analyzing what effects competing auction channels have on setting optimal list prices. To analyze the dynamics between the seller and auctioneer, we consider two cases. In the first case, we assume there is only one firm operating both the fixed list price store and the all-pay auction. In the second case, we assume there are two competing firms: one operating the fixed list price store and one operating the all-pay auction.

The main contributions of our paper are as follows. First, we illuminate the dynamics of online penny auctions as an application of second-price all-pay auctions. In contrast to the negative publicity and previous published results regarding penny auctions, our analysis indicates that consumers are in fact better off at the expense of the penny auction site. Second, we develop equilibrium bidding strategies in a private valuation framework for both first- and second-price allpay auctions when bidders have pre- and post-bidding options to consider. Our inclusion of posted prices in the all-pay auction framework and with the addition of using lost bids as credits towards posted-price purchasing is, to the best of our knowledge, a novel extension. Third, we develop optimal posted pricing policies for the seller and auctioneer and discuss the economic implications. Finally, we illustrate the effect of 'sunk-bid credit' on the distribution of both final auction price and total revenue. For readability, all proofs are relegated to the Appendix.

\section{Auction theory background}

In addition to their commercial and social aspects, auctions are interesting from a theoretical perspective. The voluminous literature on auctions and bidding mechanisms spans not only Operations Research and Economics, but also Information Systems, Marketing, Computer Science, Statistics, and Theoretical Biology. However, despite the wide proliferation of auction theory, critiques regarding limitations and overly restrictive assumptions have also been raised. A motivating example appears in the almost exclusive consideration of analyzing auctions in isolation and independent of overall context, an issue raised by Rothkopf and Harstad (1994), Pinker, Seidmann, and Vakrat (2003), Shen and Su (2007) and Haruvy et al. (2008). Rarely, if ever, do bidders lack external options when deciding whether to bid and how much to bid in an auction. This research expands the traditional auction framework and analyzes the dynamics when bidders consider external options, both before and after bidding. To establish theoretical context, we begin with a brief discourse on fundamental auction theory.

The standard private valuation, single-item auction model centers on a fixed number of bidders $\mathrm{N}$, each with i.i.d. valuation $\mathrm{V}$ drawn from distribution $F_{V}(v)=\operatorname{Pr}\{\mathrm{V} \ll \mathrm{v}\}$, with support on $[\underline{v}, \bar{v}]$. Each bidder knows only their own (realized) valuation $v$, the number of bidders $N$, and the distribution $\mathrm{F}_{\mathrm{v}}(\mathrm{v})$, but not the realized valuations of the other $\mathrm{N}-1$ bidders. Although auction formats may either be open or sealed-bid, in this paper, we focus on the sealed-bid versions. In sealed-bid auctions, each bidder places their bid in a sealed envelope. When all bids have been submitted, the auctioneer opens the bids and announces, according to the specified format, the winner and the amount the winner has to pay. Typically two auction formats are considered: first-price auction, where the highest bidder wins and pays the amount of their bid, and second-price auction, 
where the highest bidder wins but pays the amount of the second highest bid. A third and slightly more unusual format is the aforementioned all-pay auction, which comes in two general versions: the first-price all-pay auction, where everyone pays the amount they bid, but only the highest bidder wins the item; and the second-price all-pay auction, where all losing bidders pay their bid while the highest bidder, who wins the item, pays the amount of the second-highest bid. ${ }^{1}$ For all four auction formats, a bidder's decision of whether to bid and the bid amount $b$ can be illustrated by a decision tree. See the decision tree in Fig. 1, where $x_{b}$ is the price the bidder pays upon winning the auction, and $y_{b}$ is the cost the bidder incurs for losing the auction. Note that $x_{b}$ and $y_{b}$ are functions of the bid amount $b$. In a first-price and second-price auction, $y_{b}=0$, while for the two all-pay auctions $y_{b}=b$. In a first-price and first-price all-pay auction, $x_{b}=b$, while in a second-price and second-price all-pay auction, $x_{b}$ is the amount of the second highest bid. The probability of winning $p_{b}$ depends on the bid $b$.

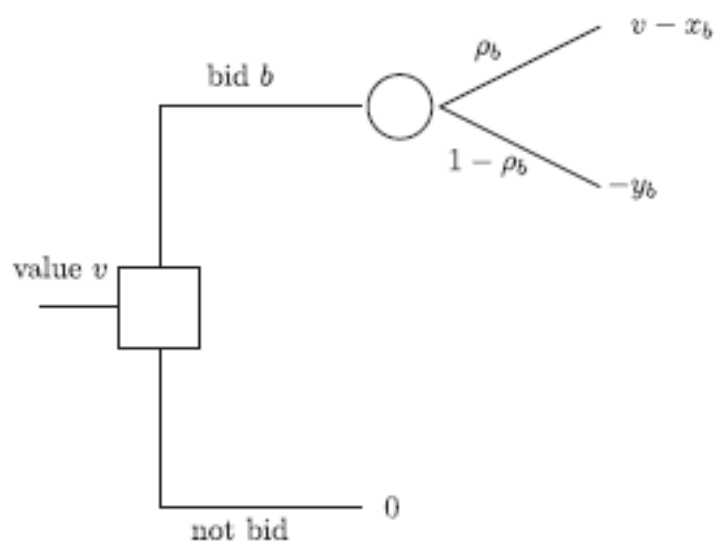

Fig. 1. Decision tree framework for bidding in an auction.

Traditionally in auction theory the primary focus lies on bidding strategies of a symmetric equilibrium, which are characterized by two factors: (1) the bid amount $b$ increases in the bidder's valuation $v$, thus ensuring that the bidder with the highest valuation wins; and (2) no individual bidder has an incentive to deviate from the bidding strategy, given that the other $N-1$ bidders adhere to it. The classic and well-established Nash equilibrium bidding strategies are: (i) in a firstprice auction, $b=E\left[V_{(1)} \mid V_{(1)}<v\right]$; (ii) in a second-price auction, $b=v$; (iii) in a first-price all-pay auction, $\mathrm{b}=\operatorname{Pr}\left\{\mathrm{V}_{(1)}<\mathrm{v}\right\} \times \mathrm{E}\left[\mathrm{V}_{(1)} \mid \mathrm{V}_{(1)}<\mathrm{v}\right]$; and (iv) in a second-price allpay auction, $\mathrm{b}=\int_{\underline{\underline{v}}}^{v} x \lambda \mathrm{v}_{(1)}(\mathrm{x}) \mathrm{dx}$, where $V\left({ }_{1}\right)$ is the highest valuation from the other $N-1$ bidders, and $\lambda_{v(1)}(\cdot)$ is the hazard rate function of $V_{(1)}$. A striking difference between second-price all-pay auctions and the other three auction formats is that, in the latter types, bidders never bid above their valuations; however, in a second-price all-pay auction bidders with 'high' valuation may bid an arbitrarily high amount. This particular bidding phenomena is often observed by professors when conducting the Dollar Auction

\footnotetext{
${ }^{1}$ Based on applications from theoretical biology, second-price all-pay auctions are often referred to as war of attrition. In this paper, we use the term 'second-price allpay auction'.
} 
in a class-room setting.

Despite the differences in bidding strategies across the four auction formats, the revenue equivalence theorem states that the expected surplus for the bidder and the expected revenue for the seller remains the same (Vickrey, 1961; Myerson, 1981; Riley \& Samuelson, 1981). Furthermore, the probability of winning is the same in each auction format, namely $p_{b}=\operatorname{Pr}\left\{\mathrm{V}_{(1)}<\mathrm{v}\right\}$. For more general background on auctions, see Krishna (2002); for more details regarding bidding in all-pay auctions, see Milgrom and Weber (1985) and Krishna and Morgan (1997). Rather than focusing on direct applications of the auction format per se, the extant literature tends to use all-pay auctions as a framework for a diverse collection of applications, including animal conflict and evolution (Maynard Smith, 1974; Bishop, Cannings, \& Maynard Smith, 1978), arms race (O'Neil, 1986), and lobbying (Baye, Kovenock, \& de Vries, 1993; Anderson, Goeree, \& Holt, 1998). For an experimental study that compares the results from Anderson et al. (1998) with empirical results see Gneezy and Smorodinsky (2006). Finally, we highlight the distinction between pay-to-bid and (multi-unit) pay-asbid auctions, where in the latter all winning bidders pay the same price. For an application of pay-asbid auctions to electricity markets see Swider and Weber (2007).

Two papers similar to ours that also consider the operational aspects of selling through dual channels include Etzion, Pinker, and Seidmann (2006) and Caldentey and Vulcano (2007). Both papers are motivated by online, multi-unit auctions competing with a fixed list price store. Our paper and results complement the insights of these authors, although some key differences do exist. Primarily, as motivated by eBay, these authors consider a dual-channel setting with a fixed list price and a multi-unit uniform price auction (where the winning bidders all pay the price of the highest non-winning bid), while we consider a setting where the competing auction channel is a single-unit all-pay auction (as motivated by online penny auctions). Naturally, the auction format will significantly affect the bidding strategies of the bidders. In particular, unlike the bidding strategy of Etzion et al. (2006) and Caldentey and Vulcano (2007), where bidders do not bid above the fixed list price, in our study's second-price all-pay auction setting, the fixed list price does not act as an upper bound on bidders' bids. Instead, in our setting, the fixed purchase price the auctioneer offers to losing bidders act as the upper bound. Interestingly there is no upper bound on the post-bidding purchase price. Furthermore, we show that with traditional auction formats, such as those in Etzion et al. (2006) and Caldentey and Vulcano (2007), the auctioneer is, in effect, not interested in offering post-bidding purchase options.

\section{Online penny auctions as second-price all-pay auctions}

In contrast to the negative publicity we mentioned in our introduction and to the results achieved by Platt, Price, and Tappen (2013), Augenblick (2011), Hinnosaar (2013), Byers, Mitzenmacher, and Zervas (2010), who also analyzed online penny auctions, our results show that bidders derive a positive expected surplus at the expense of a negative expected net revenue for the penny auction site. Similar to all modeling papers, our results provide insights only to the degree that the model assumptions are reasonably realistic. The three main assumptions we impose are: (1) penny auction sites source their items at retail, (2) bidders follow the proposed bidding strategy, and (3) penny auctions can be modeled as standard auctions. An auction is standard if the highest bidder is guaranteed to win Krishna (2002, p. 29).

The first assumption (i.e., that penny auction sites source their items at retail), served as the 
original business model of, for instance, swoopo.com. Recently, some penny auction sites appear to source their items at wholesale prices. However, even if sourcing at wholesale prices could provide the auctioneer with a positive expected profit, the auctioneer's profit margin will be dictated by the fixed list price. We elaborate on this point in Section 5.2. Regarding the second assumption (i.e., that bidders follow the proposed bidding strategy), deriving the equilibrium bid is non-trivial and, furthermore, is sensitive to correct estimation of various parameters. For instance, it is easy to show that bidders following the proposed equilibrium bidding strategy but underestimating the total number of bidders $N$ will overbid. The effect from overbidding would generate a positive expected profit for the auctioneer. On the other hand, over time, one would expect the effect from consistent overbidding to level off. ${ }^{2}$ Furthermore, the second assumption is standard in auction theory, and its limitations are not exclusive to our paper. The third assumption (i.e., that penny auctions can be modeled as standard auctions) is more technical and requires further elaboration.

Strictly speaking, the current format of most penny auctions is non-standard in that the winner is the bidder who places the last bid (i.e., the winner does not necessarily have to be the bidder who spends the most). One might conjecture though that, in practice, the main bidding activity and, in particular, counter-bidding takes place close to the end of the auction and that, consequently, the bidder who places the most bids does indeed win. Furthermore, most penny auction sites provide a service where bidders enter the maximum amount they are willing to spend, and then the auction site will monitor and bid as minimally required on behalf of the bidder. This service can be related to what is referred to as proxy bidding on eBay. Examples include BidBuddy on dealdash.com, beezid sniper on beezid.com, Bid-O-Matic on quibids.com, and bid butler on the former swoopo.com and Auto-bid on the former offandaway.com. Although these features do not guarantee penny auctions to be standard, it would seem that in reality, they are.

Deciding whether or not penny auctions constitute de facto standard auctions is an interesting and legally relevant empirical question but one that we do not seek to answer in this paper. Nevertheless, to gain some insight, we analyzed the bidding data presented in Byers et al. (2010). The data-set includes 2,541,332 bids from 7353 swoopo.com auctions. Our objective was to see how often the winner of the auction was the bidder with the most, second most, or third most placed bids. The results were that in $62 \%, 11 \%$, and $7 \%$ of the auctions the winner was the bidder with the most, second most, and third most bids, respectively. (The fourth and fifth most placed bids were $5 \%$ and $3 \%$, respectively.) In other words, in about $80 \%$ of the auctions, the winner was a bidder with the top three most placed bids. There are many interesting empirical analyses that could be conducted to further explore what factors influence the bid distributions of the winners and how they do so, but we leave this question for subsequent research. Proxy bidding services enable penny auctions sites to, in effect, operate as a second-price all-pay auction. Specifically, for all bidders with registered proxy bids, penny auction sites may simply ensure a rotation in each bidding round and wait until the auction clock has expired before the proxy bids counter-bid the manually placed bids;

\footnotetext{
2 Anecdotal stories reveal cases of 'strategic' underbidding, where unscrupulous, 'self-colluding' bidders set up two accounts and bid against themselves in an effort to deter others from bidding. After having bid a few times against themselves, thus making everyone else believe they are observing a bidding war, the unscrupulous bidder stops and wins the auction at a significant discount. Conversely, it may be the seller that is unscrupulous. It should be fairly obvious that the incentives for shillbidding (i.e., when an auctioneer secretly employs an accomplice to bid in order to drive up the auction price) are much higher in penny auctions than in, for instance, eBay-type auctions. Note though that shill-bidding and establishing two accounts to counter-bid against oneself is a fraudulent and illegal practice.
} 
however, the actual process remains unknown. ${ }^{3}$

\section{Model framework}

We consider a setting where bidders have access to two sales channels: a seller selling at a fixed list price, and an auctioneer hosting an all-pay auction. In the fixed list price channel, bidders can buy the item for $p_{1}$. For the all-pay auction channel, we consider two versions: first-price and second-price. In the first-price version, bidders place a bid $b$, and if their bid is the highest, they win the item and pay $b$, but if their bid is not the highest they still pay $\mathrm{b}$. In the second-price version, bidders place $a$ bid $b$, which they forfeit if it is not the highest bid; however, if their bid is the highest, they win the item at the price of the second-highest bid. Regardless of the all-pay version, bidders who lose out in the auction can choose to either: (1) accept the loss of $b$ and do nothing, or (2) return to the store and buy the item at $p_{1}$.

Later in our study, we consider a modified all-pay auction channel where non-winning bidders can use their failed bid $b$ as a credit towards purchasing the item at $p_{2}$ from the auctioneer. In other words, in the modified setting we consider three post-bidding options for non-winning bidders: (1) do nothing, (2) buy from the seller at $p_{1}$ (but without any credit from the failed bid), or (3) buy from the auctioneer at $p_{2}$ using their bid $b$ as a credit (i.e., pay an additional $p_{2}-b$ ). We implicitly assume that the credit provided to bidders cannot be negative. That is, bidders who place a bid $b>\mathrm{p}_{2}$, are not reimbursed $b-\mathrm{p}_{2}$, and thus, the auctioneer sells the item for $\max \left\{\mathrm{p}_{2}-b, 0\right\}$.

Bidders arrive with a realized valuation $v$ and know there are $N \gg 1$ other bidders with valuation drawn i.i.d. from $F_{v}(v)=\operatorname{Pr}\{\mathrm{V} \ll v\}$, with support on $[\underline{v}, \bar{v}]$. Note that in order to simplify the notation in the analysis, we assume there are $N+1$ total bidders. Our main interest lies in characterizing a symmetric equilibrium in the bidding/buying strategy. Therefore, for the remainder of the paper, we define $p_{v}$ as the probability that a bidder with valuation $v$ has the highest valuation and hence wins the auction, $\operatorname{p}_{v}=\operatorname{Pr}\left\{V_{(1)}<v\right\}=\left(F_{v}(v)\right)^{N}$, where $V_{(1)}$ is the highest order statistic of the other $N$ bidders' valuation.

\section{Bidding/buying strategy in first-price all-pay auctions}

We start by analyzing the bidding and buying strategy for the first-price version of the all-pay auction channel and when the bidders who lose out can buy the item from the seller only. See panel A of Fig. 2, where $x_{b}=b$. A bidder with valuation $v>p_{1}$ will never just forfeit their bid if they lose the auction; that is, if they lose they would always be better off buying the item at $p_{1}$. Consequently, standard bidding strategies from auction theory are not immediately applicable. On the contrary, we propose that auction participants bid a given fraction of $\mathrm{p}_{1}$ - namely, a fraction representing the probability that their valuation is the highest, as well as a constant representing the expected surplus of the buyer with $v=p_{1}$. For bidders with $v \ll p_{1}$, it will never be optimal to buy the item at $p_{1}$, neither from the outset nor after having lost an auction. It therefore follows that bidders with $v$ $\ll p_{1}$ face a traditional auction theory framework and, hence, should bid accordingly. We formally summarize this result in the following lemma.

Lemma 1. Assume there are $N+1$ bidders and two sales channels: (1) a fixed list price $p_{1}$ (2) a first-

3 We contacted several prominent online penny auctions to clarify their specific bidding transaction rules, but in terms of their non-specific online documentation, all responses were vague. 
price all-pay auction. If a bidder with valuation $v$ acts as follows,

1. if $v \leqslant p_{1}$, bid $b=\rho_{v} \mathrm{E}\left[V_{(1)} \mid V_{(1)}<v\right]$, and, if lose, do nothing,

2. if $v>p_{1}$, bid $b=\rho_{v} p_{1}-\phi_{p_{1}}$, and, if lose, then buy at $p_{1}$,

where $\phi_{p_{1}}$ is the expected surplus for the bidder with valuation $v=p_{1}$ (i.e. $\phi_{p_{1}}=\rho_{p_{1}}\left(p_{1}-\mathrm{E}\left[V_{(1)} \mid V_{(1)}<p_{1}\right]\right)$ ), then the strategy is a Nash equilibrium.

Given the above bidding strategy, the expected surplus for a bidder with valuation $v>p_{1}$ is

$$
\begin{aligned}
\phi_{v} & =\rho_{v}\left(v-\rho_{v} p_{1}+\phi_{p_{1}}\right)+\left(1-\rho_{v}\right)\left(v-p_{1}-\rho_{v} p_{1}+\phi_{p_{1}}\right) \\
& =v-p_{1}+\phi_{p_{1}} .
\end{aligned}
$$

For a bidder with valuation $v 6 p_{1}$, the expected surplus is

$$
\begin{aligned}
\phi_{v} & =\rho_{v}\left(v-\rho_{\nu} \mathrm{E}\left[V_{(1)} \mid V_{(1)}<v\right]\right)-\left(1-\rho_{v}\right)\left(\rho_{\nu} \mathrm{E}\left[V_{(1)} \mid V_{(1)}<v\right]\right) \\
& =\rho_{v}\left(v-\mathrm{E}\left[V_{(1)} \mid V_{(1)}<v\right]\right) .
\end{aligned}
$$

In other words, for all bidders, the expected surplus is higher with the added all-pay auction channel than if there were a fixed list price store only. The bidders with low valuation derive some surplus from having the chance of winning an item they cannot afford, while the high valuation bidders receive the added expected surplus $\emptyset_{\mathrm{p} 1}$. Since bidders with $v>p_{1}$ receive the added benefit $\emptyset_{\mathrm{p} 1}$, they have no incentive to bid as if their valuation were below $p_{1}$, a condition that ensures they do not deviate from the equilibrium bidding strategy. It should be stressed that the expected surplus is that which results from following the bidding and buying strategy to its conclusion, and not the expected surplus from participating in the auction.

We now extend the above setting and allow losing bidders the option of using their sunk bid $b$ as credit towards buying the item for $p_{2}$. See panel B in Fig. 2 , where $x_{b}=b$. This extension requires

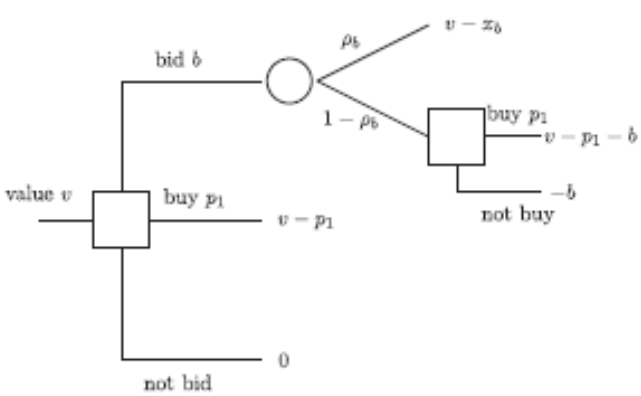

(A) All-Pay Auction with Pre- and Post-Bidding Options

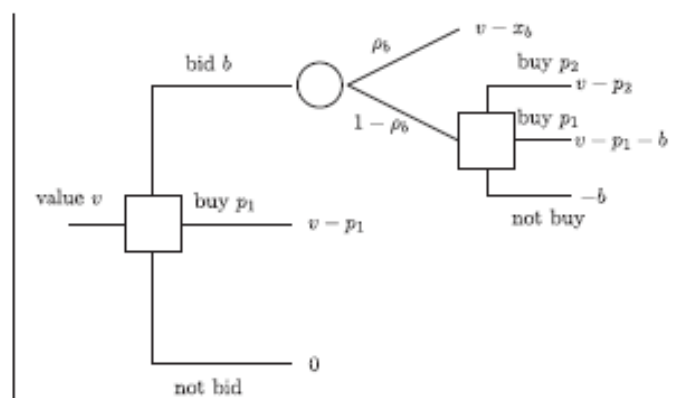

(B) Modified All-Pay with Pre- and Post-Bidding Options

Fig. 2. Illustration of bidding and buying framework. 
some clarifications: First, it is of interest to consider only those prices such that $p_{2}>p_{1} .{ }^{4}$ Second, as mentioned above, no buyer would ever bid more than $\mathrm{p}-\mathrm{j}$, regardless of their valuation $v$. Third, buyers with valuation $v>p_{1}$ will not just forfeit their bid if they lose the auction, since they still have an option of buying it at either $p_{2}$ or $p_{1}$. Fourth, although buyers with $v<p_{1}$ will never buy the item at $p_{1}$, upon losing the auction, they might have an incentive to buy the item at $p_{2}$. This situation would arise if their bid was more than $p_{2}-v$, in which case rather than take the loss $b$ they take the loss $p_{2}-v$. However, at equilibrium, and assuming the auctioneer sources from the seller (see Section 5.2), this situation will never occur because the auctioneer has no incentive to offer a losing bidder the item at a price $p_{2}$ such that $p_{2}-b<p_{1}$. The bid $b$ can be seen as a "sunk" revenue, and thus, the optimal decision is to buy the item from the seller at $p_{1}$ only if the net revenue is positive (i.e., if $\left.p_{2}-b>p_{1}\right) .{ }^{5}$ Therefore, without loss of generality, we may assume that the seller commits to a price $p_{2} \gg p_{1}+b_{p 1}=p_{1}+p_{p 1} E\left[V_{(1)} \mid V_{(1)}<p_{1}\right]$, where $b_{p 1}$ is the bid by a bidder with valuation $v=p_{1}$ and is defined according to Lemma 1. Given this assumption, there exists a threshold $v^{+}=F^{-1}\left(\left(p_{2}-p_{1}\right.\right.$ $\left.\left.+\emptyset_{\mathrm{p} 1}\right) / \mathrm{p}_{1}^{1 / \mathrm{N}}\right)$ such that if $\mathrm{v} \ll \mathrm{v}^{+}$, then the buyer should act according to Lemma 1 , while if $\mathrm{v}^{+}<\mathrm{v}$ then the buyer should first bid $b=\left(p_{1}-\left(1-p_{v}\right) p_{2}-/ \emptyset_{p 1}\right) / p_{v}$ and, if unsuccessful, buy at $p_{2}$. Note, however, that the threshold $v^{+}$depends on the particular values of $p_{1}$ and $p_{2}$ and may collapse to $p_{1}$ or $v$. We formally summarize the result.

Lemma 2. Assume there are $N+1$ bidders and two sales channels: (1) a fixed list price $p_{1},(2)$ a firstprice all-pay auction where losing bidders may use their bid as a credit to buy the item for $p_{2}$ (and $p_{2}$ $\left.\gg p_{1}+p_{p 1} E\left[V_{(1)} \mid V_{(1)}<p_{1}\right]\right)$. If a bidder with valuation $v$ acts as follows,

1. if $\mathrm{v} \ll \mathrm{v}^{+}$, act according to Lemma 1 ,

2. if $v>v^{+}$, bid $b=\left(p_{1}-\left(1-p_{v}\right) p_{2}-/ \emptyset_{p 1}\right) / p_{1}^{1 / N}$, and, if lose, buy at $p_{2}$, where $v^{+}=\max \left\{p_{1}, F^{-1}\left(\min \left\{1,\left(p_{2}-p_{1}+\emptyset_{p 1}\right) / P_{1}^{1 / N}\right\}\right)\right\}$, then the strategy is a Nash equilibrium.

With the added option, the expected surplus for a bidder with valuation $v>v^{+}$is, $\emptyset_{v}=P_{v}(v-$ $\left.\left(p_{1}-\left(1-P_{v}\right) p 2-\emptyset_{p 1}\right) / P_{v}\right)+\left(1-p_{v}\right)\left(v-p_{2}\right)=v-p_{1}+\emptyset_{p 1}$, while for the buyers with $v \ll v^{+}$, the expected surplus is the same as before. In other words, although adding $p_{2}$ segments the buyers with $v>p_{1}$ into two different bidding-strategy groups, their expected surplus does not change. While the expression for $v^{+}$appears complicated, it simply represents the valuation $v$ at which $p_{1}+b_{v}=p_{2}$; that is, the point at which a bidder is indifferent between: (1) forfeiting the bid $b_{v}$ and buying the item at retail for $p_{1}$, or (2) using the bid $b_{v}$ as credit towards buying the item from the auctioneer at $p_{2}$. As mentioned above, depending on the particular values of $p_{1}$ and $p_{2}$, the threshold that segments the high-valuation buyers may or may not exist. That is, if $\mathrm{p}_{2}$ is too high then $\mathrm{v}^{+}$collapses to $\bar{v}$, resulting in only one type of high-valuation buyers. An upper bound on $\mathrm{p}_{2}$ in order to ensure the segmentation is provided in the following corollary.

Corollary 1. For the first-price all-pay auction channel scenario, if $p_{2} \gg 2 p_{1}$, no one will buy the item at $p_{2}$.

Thus, if $p_{2}$ is twice as high as $p_{1}$, then no one will buy at $p_{2}$, so there is no point in offering the

\footnotetext{
${ }^{4}$ Anecdotal motivation includes auctions observed on swoopo.ca for Sony Playstation 3 (250 gigabyte) consoles. In June, 2010 , Swoopo offered them at $\$ 389$, while, for instance, BestBuy.ca was selling them at $\$ 349.99$.

${ }^{5}$ We would like to acknowledge one of the reviewers for providing this insight.
} 
price $\mathrm{p}_{2}$. It should be noted that the upper bound in Corollary 1 is not the minimum that is required for the result to hold. Since the buyers with $v>p_{1}$ are given the added surplus of $\emptyset_{\mathrm{p} 1}$, the minimum bound for the result to hold is $p_{2} \gg 2 p_{1}-\emptyset_{p 1}$.

\section{Bidding/buying strategy in second-price all-pay auctions}

Next, we consider the bidding and buying strategy for the second-price version of the all-pay auction channel. Similar to the first-price version, we first consider the setting where a bidder who loses the auction may purchase the item from the retailer. See panel A of Fig. 2, where $x_{b}$ is the amount of the second highest bid. Similar to above, a bidder with valuation $v>p_{1}$ will never just forfeit their bid if they lose the auction, so standard results from auction theory do not apply. Furthermore, it is intuitive that, given the difference in auction format, the results from Lemma 1 do not apply. On the other hand, for bidders with $v \ll p_{1}$, it will never be optimal for bidders to buy the item at $p_{1}$, and hence, the bidder faces a traditional auction theory framework and should bid accordingly. We formally summarize the bidding/buying strategies in the following lemma.

Lemma 3. Assume there are $N+1$ bidders and two sales channels: (1) a fixed list price $p_{1},(2)$ a second-price all-pay auction. If a bidder with valuation $v$ acts as follows,

1. if $\vee 6 \mathrm{p}_{1}$, bid $\mathrm{b}_{\mathrm{v}}=\int_{0}^{v} x \lambda v_{(1)+}(\mathrm{x}) \mathrm{dx}$, and, if lose, do nothing,

2. if $v>\mathrm{p}_{1}$, bid $\mathrm{b}_{\mathrm{v}}=\mathrm{b}_{\mathrm{p} 1}+\int_{p 1}^{v} p_{1} \lambda v_{(1)}(\mathrm{x}) \mathrm{dx}$, and, if lose, buy at $\mathrm{p}_{1}$,

where $\lambda v_{(1)}(\mathrm{x})$ is the hazard rate function of $\mathrm{V}_{(1)}$, then the strategy is a Nash equilibrium.

Lemma 3 is partially derived from the equilibrium bidding strategies of first-price all-pay auctions and through applying the revenue equivalence theorem. Many of the subsequent results are derived through the same basic technique (i.e., by applying the revenue equivalence theorem to our result for the first-price all-pay auction version). Consequently, given the results of Lemma 1 , the expected bidder surplus $\emptyset_{\mathrm{v}}$, for a bidder with valuation $v \ll P_{1}$ in a second-price all-pay auction is also given by $\emptyset_{v}=p_{v}\left(v-E\left[V_{(1)} \mid V_{(1)}<v\right]\right)$, while for a bidder with valuation $v>p_{1}$, the expected surplus is given by $\emptyset_{v}=v-p_{1}+\emptyset_{p 1}$.

We now extend the above setting and allow losing bidders the option of using their sunk bid $b$ as a credit towards buying the item for $p_{2}$. See panel B of Fig. 2, where $x_{b}$ is the amount of the second highest bid. Similar to the first-price all-pay auction setting, we can assume the auctioneer sets $\mathrm{p}_{2} \gg \mathrm{p}_{1}+\mathrm{b}_{\mathrm{p} 1}=\mathrm{p}_{1}+\int_{0}^{P} x \lambda v_{(1)}(x) d x$, where $\mathrm{b}_{\mathrm{p} 1}$ is the bid by a bidder with valuation $\mathrm{v}=\mathrm{p}_{1}$ and is defined according to Lemma 3 . Given this assumption, there exists a threshold $v^{\text {-, such }}$ that if $v \ll v^{-}$, the bidder should act according to Lemma 3 , while if $v>v^{*}$, the bidder should simply bid $b=p_{2}$, and if unsuccessful buy at $p_{2}$. We formally summarize this scenario as follows. 

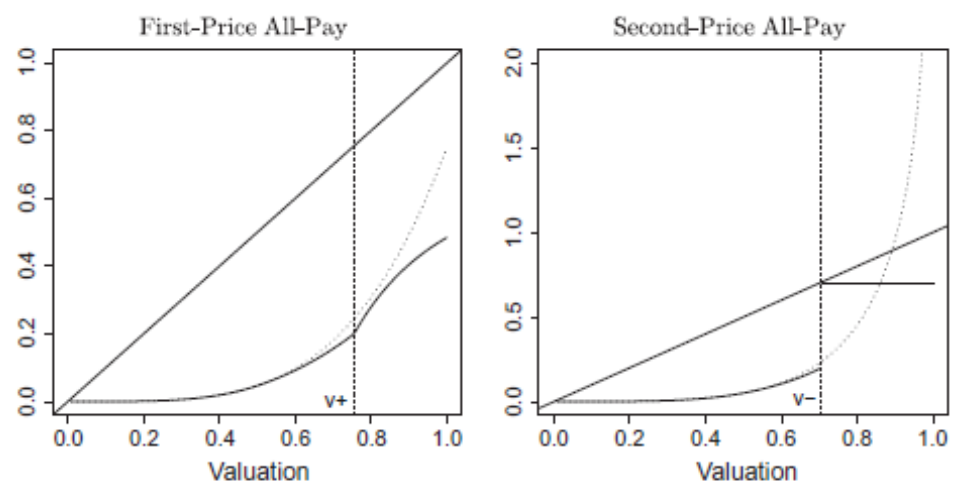

(I) $p_{1}=.50, p_{2}=.70, v^{+}=.76, v^{-}=.71$
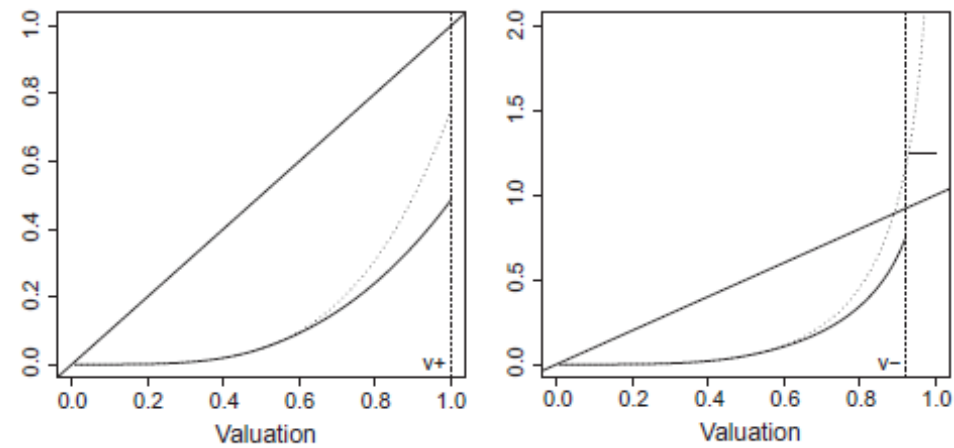

(II) $p_{1}=.50, p_{2}=1.25, v^{+}=1.0, v^{-}=.92$

Fig. 3. Numerical illustration of first-price (left) and second-price (right) all-pay auction bidding strategy for four bidders; $V \sim U[0,1]$.

Lemma 4. Assume there are $N+1$ bidders and two sales channels: (1) a fixed list price $p_{1}$, (2) a second-price all-pay auction where the losing bidders may use their bid as a credit to buy the item for $p_{2}$ (and $\left.P_{2} \gg P_{1}++\int_{0}^{P} x \lambda v_{(1)}(\mathrm{x}) \mathrm{dx}\right)$. If a bidder with valuation $v$ acts as follows,

1. if $v \ll v$, act according to Lemma 3,

2. if $v>v$, bid $b=p_{2}$, and, if lose, buy at $p_{2}$,

where $v^{-}=F^{-1}\left(1-\exp \left(p_{1}+b_{p 1}-p_{2}\right) p_{1}+\ln \left(1-\left(F\left(p_{1}\right)\right)^{N}\right)^{1 / N}\right)$, then the strategy is a Nash equilibrium.

Similar to the first-price setting, the added $p_{2}$ and threshold $v$ do not change the expected surplus for bidders with valuation $v>v^{-}$; the expected surplus remains $\emptyset_{v}=v-p_{1}+\emptyset_{\mathrm{p} 1}$. Furthermore, although the expression for $v^{-}$may appear rather complicated, it simply represents the point of indifference between accepting the sunk bidding cost and purchasing at $p_{1}$ versus using the sunk bidding cost as a credit and purchasing at $p_{2}$. Observe that $v^{-}$is increasing in $p_{2}$ and that there is no upper bound on $\mathrm{p}_{2}$ such that $\mathrm{v}^{-}$collapses to $\mathrm{v}$. In other words, the auctioneer may set an arbitrarily high $p_{2}$, including above $\bar{v}$, and still there are bidders who will bid $p_{2}$ and, if unsuccessful, buy at $p_{2}$. This scenario can be contrasted to the first-price setting, or a strict second-price auction setting without $p_{2}$ (Etzion et al., 2006), where bidders never bid $b>p_{1}$. On the other hand, if $p_{2}$ is 'too low', 
then no one will buy the item from the retail store at $p_{1}$. We summarize this outcome in the following corollary.

Corollary 2. For the second-price all-pay auction channel scenario, if $p_{2}=p_{1}+b_{p 1}$, no one will buy the item at the store for the fixed list price $p_{1}$.

From the perspective of the bidders (or society), auction theory usually seeks to address the issue of efficiency (i.e., that the object ends up with the bidder who, ex post, values it the most). In our setting, all bidders with valuation $v>p_{1}$ are guaranteed to receive an item, either through winning the auction or through buying from one of the post-bidding options. Therefore, the added auction channel provides no gain in efficiency for those bidders. When the valuation of all bidders is less that $p_{1}$, then the added auction channel does provide efficiency gain. We point out that the gain in efficiency comes at the loss of the auctioneer, a fact that leads us to the other topic of interest namely the seller's and auctioneer's expected revenue, which we discuss in Section 5. However, we first illustrate Lemmas 1-4 with two numerical examples, and we compare the bidding strategies to traditional first- and second- price all-pay auction bidding strategies.

\section{Numerical illustration for uniform distributed valuations}

To gain insight into bidders' bidding strategies, we illustrate with two numerical examples based on four bidders and valuations uniformly distributed on $[0,1] ; F_{v}(v)=v$, for $v \in[0,1]$. The two numerical examples are based on the following prices: (I) $p_{1}=.50, p_{2}=.70$, and (II) $p_{1}=.50, p_{2}=1.25$. The two examples have the following thresholds: (I) $\mathrm{v}^{+}=.76$ and $\mathrm{v}^{-}=.71$; and $(\mathrm{II}) \mathrm{v}^{+}=1.0$ and $\mathrm{v}^{-}=.92$. In the first-price all-pay auction scenario, there are three types of bidders: (1) bidders with $\mathrm{v} \ll \mathrm{p}_{1}$ who bid $b_{v}=\mathrm{v}^{\mathrm{N}} \frac{N}{N+1} \mathrm{v}$ and, if they lose, do nothing; (2) bidders with $\mathrm{p}_{1}<\mathrm{v} \ll \mathrm{v}^{+}$who bid $b_{v}=v^{N} p_{1}-$ $\frac{P_{1}^{N+1}}{N+1}$ and, if they lose, buy the item for $p_{1}$; and (3) bidders with $\mathrm{v}^{+}<\mathrm{v} \ll \overline{\mathrm{v}}$ who bid $b_{v}=\left(p_{1}-\left(1-\mathrm{v}^{N}\right)\right.$ $\mathrm{p}_{2}-\frac{P_{1}^{N+1}}{N+1} / \mathrm{v}^{N}$ and, if they lose, buy the item at $\mathrm{p}_{2}$. Note that when $p_{2}=\$ 1.25$ and $\mathrm{v}+\equiv \mid \bar{v}$, then the third category does not exist. In the second-price all-pay auction scenario there are also three types of bidders: (1) bidders with $v \ll \mathrm{p}_{1}$ who bid $b_{v}=\int_{0}^{v} N x^{\mathrm{N}} /\left(1-\mathrm{x}^{\mathrm{N}}\right) d x$ and, if they lose, do nothing; (2) bidders with $\mathrm{p}_{1}<v \ll \mathrm{v}^{-}$who bid $b_{v}=\mathrm{b}_{\mathrm{p} 1}+\int_{p 1}^{v} p_{1} N x^{\mathrm{N}} /\left(1-\mathrm{x}^{\mathrm{N}}\right) d x$ and, if they lose, then buy the item for $p_{1}$; and (3) bidders with $v^{-}<v<\bar{v}$ who bid $b_{v}=p_{2}$ and, if they lose, then buy the item at $p_{2}$.

Fig. 3 displays the bidding strategy for the first-price (left) and second-price (right) format as a function of a bidder's valuation. Note that the vertical axes for the left and right graphs are scaled differently. In each graph, the solid curve represents the bidding strategy in the all-pay auction with pre- and post-bidding options, while the dotted curve represents the equilibrium bidding in a traditional all-pay auction framework (i.e., without fixed list price options). The 45-degree reference line in the each graph highlights bidders who bid below/above their valuation and coincides with the equilibrium (truthful) bidding strategy of a traditional second-price auction (i.e., not the all-pay format and with no fixed price purchase option).

A couple of interesting observations arise. First, in the first-price scenario, regardless of whether the $p_{2}$ option is available, nobody bids above the fixed list price $p_{1}$. In contrast, in the second-price scenario, the fixed list price $p_{1}$ does not act as an upper-bound, but instead, the auctioneer list price $p_{2}$ acts as the upper bound. Second, in the first-price scenario, nobody bids 
higher than they would if there were no external retail options. That is, we observe in the left graphs that the solid lines are below the dotted lines, which indicates that bidders will shade their bids more due to the purchasing options. In contrast, in the second-price scenario, depending on the value of $p_{2}$, bidders may bid more than they would if there were no purchasing options. This observation is illustrated in case (I), in which bidders bid more compared to an auction framework with no purchasing options (i.e., there is a segment where the solid line is above the dotted line). This effect is due to the credit from the sunk bid $b$ (i.e., if they lose, they do not incur a loss but receive a positive surplus from purchasing the item using their credit from the sunk bid). However, when $\mathrm{p}_{2}$ is 'high', as in case (II), then none of the bidders bids more than they would if there were no purchasing option.

Fig. 4 displays the expected surplus for both numerical examples and both all-pay auction formats. The solid curve represents the expected bidder surplus in the all-pay auction with pre- and post-bidding options, while the dotted curve represents the bidder surplus in a traditional all-pay auction framework (i.e., without purchasing options). As we know from the revenue equivalence theorem, the expected surplus is the same for the first- and second-price all-pay auction format. We observe that for bidders with $v>p_{1}$, the expected surplus is virtually $v-p_{1}$. In other words, the incremental gain in expected surplus that comes from introducing an all-pay auction channel to a setting with only a fixed list price channel is rather small. On the other hand, the incremental gain in expected surplus that comes from having a fixed list price option in addition to an all-pay auction channel is significant. We see that there is a gap between the dotted curve and the solid curve, which furthermore appears to be growing in $v$.

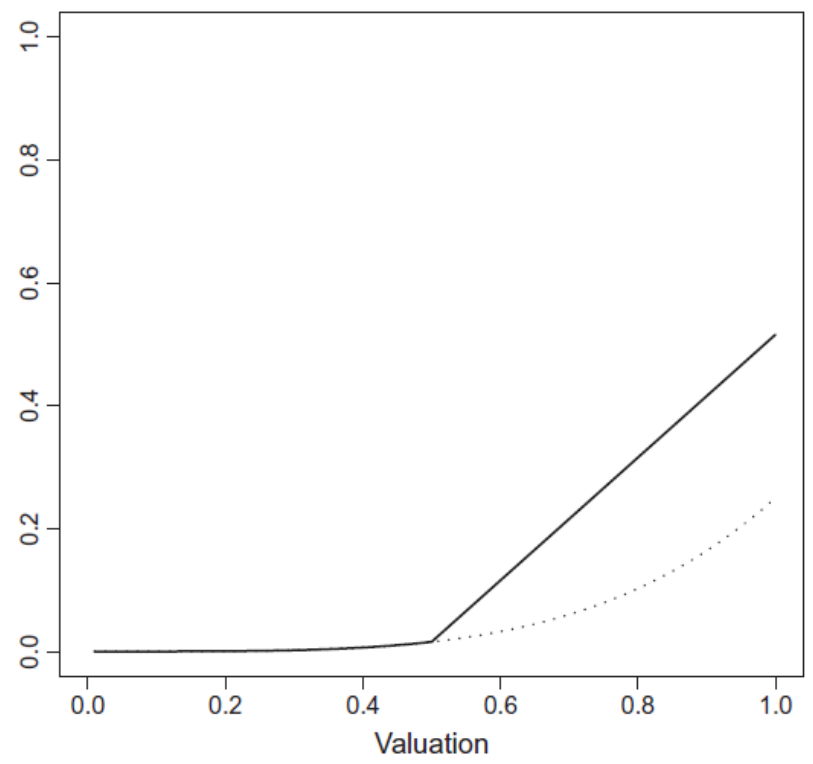

Fig. 4. Numerical illustration of expected surplus for four bidders; $V \sim U[0,1]$.

\subsection{Comparison to traditional first- and second-price auctions}

Etzion et al. (2006) consider a setting where the auction channel is a traditional second-price 
auction and the auctioneer does not offer losing bidders a purchase option (i.e., panel A of Fig. 2, where $x_{b}$ is the amount of the second highest bid, but the cost $b$ following losing the auction is zero). These authors show that a weakly- dominating bidding strategy is $b_{v}=\max \left\{v, \mathrm{p}_{1}\right\}$. If we extend their setting to include the auctioneer offering the losing bidders a purchase option of a fixed price $p_{2}$, then, trivially, $p_{2}$ can only be less than $p_{1}$. See panel B of Fig. 2 , where $x_{b}$ is the amount of the second highest bid, but the cost $b$ following losing the auction is zero. The issue is that, unlike the all-pay auction, where all bidders incur a cost of bidding, there is no cost in a second-price auction, and hence, the auctioneer does not have any forceful or credible mechanism to get bidders to pay more than the competing fixed price channel. Therefore, the only credible scenario would be if $p_{2} \ll p_{1}$. However, it can easily be shown that the optimal bidding strategy becomes $b_{v}=\max \left\{\mathrm{v}, \mathrm{p}_{2}\right\}$, that is, the same argument as the proof of Lemma 1 in Etzion et al. (2006) applies. Consequently, the auctioneer is worse off compared to not offering a post-bidding purchase option. In this scenario, the auctioneer is better off by explicitly not offering a post-purchase option or, in effect, by not offering a post-purchase option by setting $\mathrm{p}_{2}>\mathrm{p}_{1}$.

Next we consider a first-price setting (i.e., panel A of Fig. 2, where $x_{b}=b$, but the cost $b$ following losing the auction is zero). In this setting, it can be shown that a weakly-dominating bidding strategy is for bidders with valuation $\mathrm{v} \ll p_{1}$ to bid $b=\mathrm{E}\left[\mathrm{V}_{(1)} \mid \mathrm{V}_{(1)}<\mathrm{v}\right]$ and for bidders with valuation $v>p_{1}$ to bid $b=p_{1}-\emptyset_{p 1} / p_{v}$, where $\emptyset_{p 1}$ is the expected surplus of a bidder with valuation $v$ $=\mathrm{p}_{1}$ who bids $b=\mathrm{E}\left[\mathrm{V}_{(1)} \mid \mathrm{V}_{(1)}<\mathrm{p}_{1}\right]$. Similar to the argument above for the second-price auction, the first-price auctioneer would never be better off offering a post-bidding purchase option.

Expected Revenue per Consumer

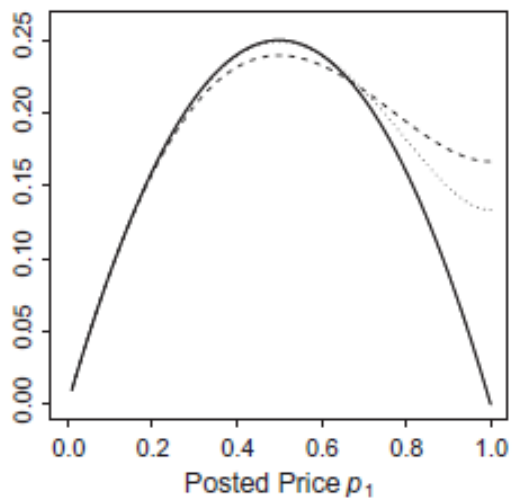

(A) Single Firm
Expected Revenue per Consumer

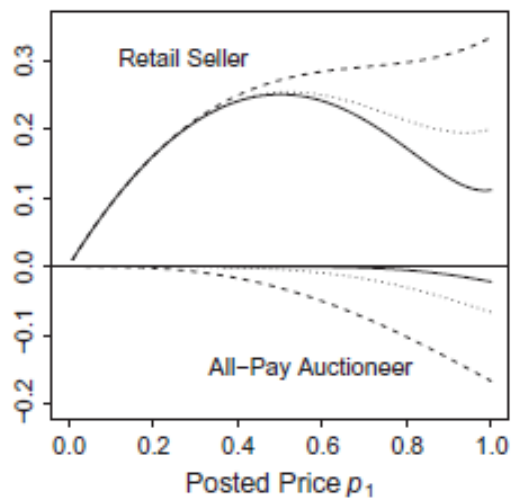

(B) Dual Firms

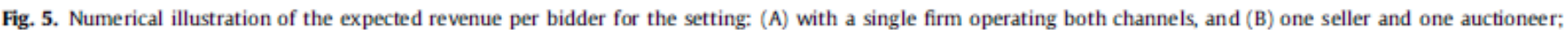

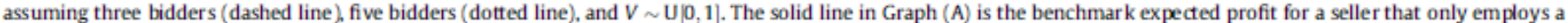
fixed list price channel (i.e. without an all-pay auction channel). The solid line in Graph (B) is the case when there are nine bidders.

By the revenue equivalence theorem, we know that the expected surplus for both the firstprice and second-price auction will be the same as for the first-price all-pay and second-price all-pay auctions. 


\section{Seller's and auctioneer's pricing problem}

Given the above bidding and buying strategy, we now consider the seller's and auctioneer's problem in setting optimal prices $p_{1}$ and $p_{2}$ to maximize expected revenue. We first consider a system where a single firm operates both the fixed list price store and the all-pay auction. Later, we extend the setting and consider a system with two firms: a seller and an all-pay auctioneer.

\section{Single firm, dual channels}

If there is only one firm, then, from non-winning bidders, the firm receives either $b_{v}, b_{v}+p_{1}$, or $p_{2}$, depending on whether the bidder's valuation is less than $p_{1}$, between $p_{1}$ and the threshold $\mathrm{v}^{+}$ (first-price setting) or $\mathrm{v}^{-}$(second-price setting), or greater than

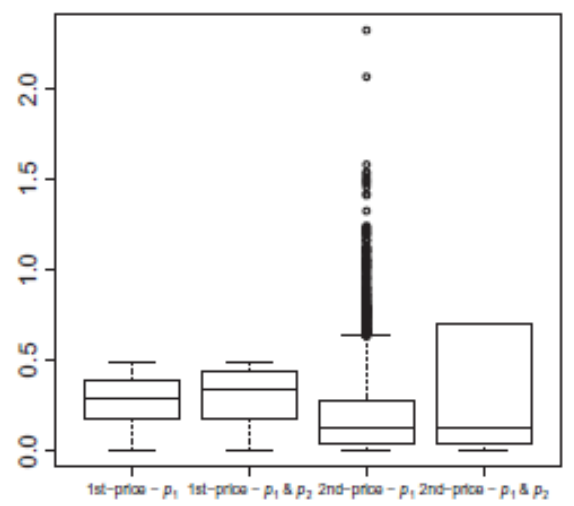

(A) Final Auction Price

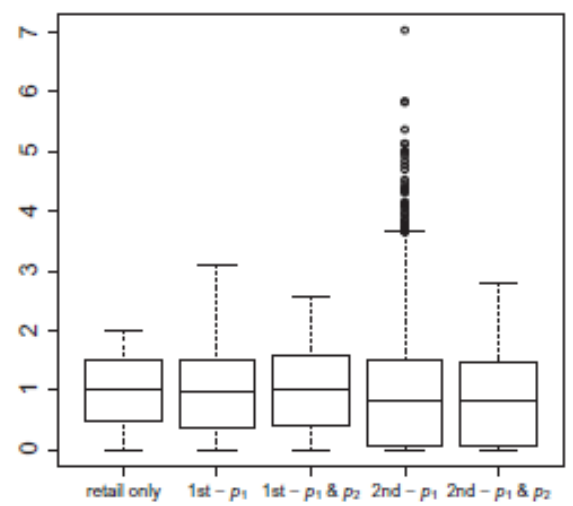

(B) Total Revenue

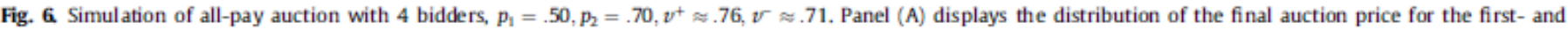

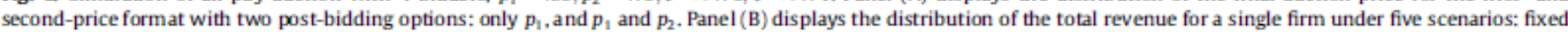

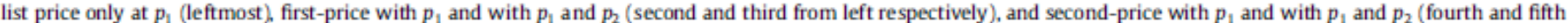
from left respectively).

$\mathrm{v}^{+} / \mathrm{v}^{-}$. If, on the other hand, a bidder wins the auction, then the firm receives either the bid $b_{\mathrm{v}}$ (firstprice setting) or the amount of the second highest bid (second-price setting). Let the firm's expected revenue (per bidder) in a first- and second-price setting be represented by $\pi_{1 s t}$ and $\pi_{2 n d}$, respectively. These expected revenues can be expressed as,

$$
\begin{aligned}
\pi_{1^{*}}= & \int_{\underline{y}}^{p_{1}} b_{v y} f(v) d v+\int_{p_{1}}^{v^{+}}\left[b_{v}+\left(1-\rho_{\nu}\right) p_{1}\right] f(v) d v \\
& +\int_{v^{+}}^{\bar{v}}\left[\rho_{\nu} b_{v}+\left(1-\rho_{\nu}\right) p_{2}\right] f(v) d v
\end{aligned}
$$

with $b_{v}$ and $\mathrm{v}^{+}$as defined in Lemmas 1 and 2 , and 


$$
\begin{aligned}
\pi_{2^{\text {af }}}= & \int_{\underline{v}}^{p_{1}}\left[\left(1-\rho_{v}\right) b_{v}+\rho_{\nu} b_{(2)}\right] f(v) d v \\
& +\int_{p_{1}}^{v-}\left[\left(1-\rho_{v}\right)\left(p_{1}+b_{v}\right)+\rho_{v} b_{(2)}\right] f(v) d v \\
& +\int_{v^{-}}^{\bar{v}}\left[\left(1-\rho_{\nu}\right) p_{2}+\rho_{\nu} b_{(2)}\right] f(v) d v,
\end{aligned}
$$

where $b_{v}$ and $v^{-}$are defined in Lemmas 3 and 4 , and $b_{(2)}$ is the conditional expected bid of the second highest bidder, given that their valuation is below $v$. A counter-intuitive result is that regardless of the all-pay auction format, the firm's expected revenue $\pi$ is independent of $p_{2}$. In other words, although $p_{2}$ may segment the bidders into different bidding-strategy categories, it does not affect the firm's expected revenue, regardless whether the all-pay auction is a first- or second-price version. We summarize this result in the following proposition.

Proposition 1. If there is one firm operating both the fixed list price channel and the all-pay auction channel (first- or second-price), then the expected revenue per bidder is independent of $p_{2}$ and given by,

$$
\begin{gathered}
\pi=\int_{\underline{v}}^{p_{1}} \rho_{\nu} E\left[V_{(1)} \mid V_{(1)}<v\right] f(v) d v+\left(p_{1}\left(1-\rho_{p_{1}}\right)\right. \\
\left.+\rho_{p_{1}} E\left[V_{(1)} \mid V_{(1)}<p_{1}\right]\right)\left(1-F_{V}\left(p_{1}\right)\right)
\end{gathered}
$$

where $\rho_{v}=\left(F_{V}(v)\right)^{N}$.

From Eq. (3), it is not immediately apparent whether the firm is better or worse off with the added all-pay auction channel. Although the firm receives an additional expected revenue of $\int_{\underline{v}}^{p 1} p_{v} E\left\{V_{(1)} \mid V_{(1)}<v\right\} f(v) d v$ and $P_{p 1} E\left\{V_{(1)} \mid V_{(1)}<p_{1}\right\}\left(1-F_{v}\left(p_{1}\right)\right)$, this comes at the expense of a lesser revenue $p_{1}\left(1-p_{p_{1}}\right)\left(1-F_{v}\left(p_{1}\right)\right)$ as compared with operating only a fixed list price channel with expected revenue of $p_{1}\left(1-F_{v}\left(p_{1}\right)\right)$. To explore this trade-off, in Section 5.3, we discuss the case when bidders' valuations are uniformly distributed. Furthermore, although the expected revenue is the same for the two different all-pay auction formats, the distribution of the revenue will be quite different, another point that we highlight in Section 5.3.

In Section 4.4, we summarized weakly-dominating bidding strategies for traditional first- and second-price auctions. It follows from the revenue equivalence theorem that Proposition 1 also applies to the first- and second-price auction. Thus, as long as the first- or second-price auctioneer does not offer a post-bidding purchase option $p_{2}<p_{1}$, then the expected revenue is given by (3).

\section{Dual firms, dual channels}

We now extend the above setting and consider a system with two firms: a seller operating the fixed list price store and an auctioneer hosting the all-pay auction. To make the revenue comparison consistent with the setting with a single firm, we assume the auctioneer purchases the goods at $p_{1}$ from the seller. The modeling motivation is that we are interested in deriving expressions for the seller's expected revenue $\pi_{r}$ and the all-pay auctioneer's expected net revenue $\pi_{\text {ap }}$ such that $\pi=\pi_{r}+$ $\pi_{a p}$. The real-world motivation is to analyze the commercial viability of the founding business model of swoopo.com. During their early years, Swoopo would only after an auction was completed 
purchase an item at retail and arrange to have it shipped directly to the winning bidder.

Recall that both the winner of the all-pay auction as well as the losers with $v>v^{+}$(first-price) or $v>v^{-}$(second-price) receive an item from the all-pay auction channel. With these changes, the expected revenue (per bidder) for the seller becomes,

$$
\pi_{r}=p_{1}\left(1-F_{V}\left(p_{1}\right)\right)+\int_{\underline{v}}^{p_{1}} \rho_{v} p_{1} f(v) d v
$$

Note that the first part of the revenue function is the expected revenue for a seller operating in a setting without the all-pay auction channel. Thus, compared to the setting when there is a fixed list price channel only, the seller is better off with the added all-pay auction channel (regardless of the specific auction format). This outcome is intuitive since we have assumed the all-pay auctioneer buys the items from the seller, and hence, when a bidder with $v \ll p_{1}$ wins the auction, positive expected revenue will result.

Since we have assumed a 'closed system' with the auctioneer buying from the seller, it follows that the expected gain for the seller must come at the expense of the all-pay auctioneer. The expected net revenue (per bidder) for the auctioneer operating a first-price all-pay auction is given by

$$
\begin{aligned}
\pi_{1^{s t} a p}= & \int_{\underline{v}}^{p_{1}}\left(b_{v}-\rho_{v} p_{1}\right) f(v) d v+\int_{p_{1}}^{v^{+}}\left(b_{v}-\rho_{v} p_{1}\right) f(v) d v \\
& +\int_{v^{+}}^{\bar{v}}\left(\rho_{v} b_{v}+\left(1-\rho_{v}\right) p_{2}-p_{1}\right) f(v) d v,
\end{aligned}
$$

with $b_{v}$ and $\mathrm{v}^{+}$as defined according to Lemmas 1 and 2 , while the expected net revenue (per bidder) in a second-price all-pay auction is given by

$$
\begin{aligned}
\pi_{2^{\text {nd }} a p}= & \int_{\underline{v}}^{p_{1}}\left(\rho_{v}\left(b_{(2)}-p_{1}\right)+\left(1-\rho_{v}\right) b_{v}\right) f(v) d v+\int_{p_{1}}^{v^{-}}\left(\rho_{v}\left(b_{(2)}-p_{1}\right)\right. \\
& \left.+\left(1-\rho_{v}\right) b_{v}\right) f(v) d v+\int_{v^{-}}^{\bar{v}}\left(\rho_{v} b_{(2)}\right. \\
& \left.+\left(1-\rho_{v}\right) p_{2}-p_{1}\right) f(v) d v
\end{aligned}
$$

with $b_{v}$ and $v$ as defined according to Lemmas 3 and 4 , and $b_{(2)}$ is the conditional expected bid of the second highest bidder, given that their valuation is below $v$. Although, from Eqs. (5) and (6), it is not immediately apparent that the auctioneer incurs an expected loss, this is indeed the case. We formally summarize this result in the following proposition.

Proposition 2. If there are $N+1$ bidders who act according to Lemmas 1 and 2 in a first-price all-pay auction or Lemmas 3 and 4 in a second-price all-pay auction, and the auctioneer buys the items from the seller at $p_{1}$, then the auctioneer's expected net revenue is always negative and given by, 


$$
\pi_{a p}=\int_{\underline{v}}^{p_{1}} \rho_{v}\left(E\left[V_{(1)} \mid V_{(1)}<v\right]-p_{1}\right) f(v) d v-\phi_{p_{1}}\left(1-F_{V}\left(p_{1}\right)\right) .
$$

Our results are based on the assumption that the auctioneer purchases the items at retail price $p_{1}$ from the store. As discussed above, this was the original business model of the first generation of penny auction sites. Since then, many penny auction sites appear to be purchasing at wholesale. Accommodating expressions (4)-(6) to a wholesale scenario is a straight forward process. First, for the seller, this scenario implies only that revenue from losing bidders with a valuation above $p_{1}$ but below the threshold $v^{+} / v^{-}$is generated. In other words, the competition from the allpay auction channel is much more pronounced and significantly reduces the seller's expected revenue. In fact, from Corollary 2 , we know that if the auctioneer sets the post-bidding price $p_{2}$ at the lower feasible bound, then the seller will have no sales. Second, for the auctioneer, the bidding strategies of consumers will not change, and hence $b_{v}, b_{(2)}$ and the integral limits in (5) and (6) remain unaffected. Instead, the only changes are with respect to the cost of the item $p_{1}$ inside the integrals. If a 'low enough' wholesale price $p_{w}$ can be secured, then the auctioneer could incur a positive expected (net) revenue. Note, though, that $b_{v}$ and the integral limit are functions of $p_{1}$, which is under the control of the seller.

Similar to the single-firm, dual-channel case, the extension to traditional first- or secondprice auction settings is immediate. In other words, by the revenue equivalence theorem, both the seller's expected revenue given by (4) and the auctioneer's expected revenue given by (7) hold in a first- or second-price auction setting.

\section{Numerical illustration for uniform distributed valuations}

To gain further insight into the seller's and auctioneer's expected revenue, we illustrate for the case when bidders' valuations are uniformly distributed on $[0,1] ; F_{v}(v)=v$, for $v \in[0,1]$. With bidders' valuations uniformly distributed on $[0,1]$, Eq. (3) becomes

$$
\pi=p_{1}\left(1-p_{1}\right)+p_{1}^{N+2} \frac{2}{N+2}-p_{1}^{N+1} \frac{1}{N+1} \text {. }
$$

The first part of Eq. (8) is the expected revenue for a firm with a fixed list price channel only, while the last two parts represent the net effect of operating the competing auction channel. Since $p_{1}<1$, we have $P_{1}^{N+2}<P_{1}^{N+1}$, but, on the other hand, for all $N<\infty, 2 /(N+2)>1 /(N+1)$. Therefore, from Eq. (8), it remains unclear whether the firm is strictly worse off with the added all-pay auction channel. To gain some intuition before deriving the formal results, we illustrate with numerical examples.

Graph A in Fig. 5 displays Eq. (8) for the case with three and five bidders. The horizontal axis represents $p_{1}$, while the vertical axis represents the expected revenue $\pi$. The dashed line represents the case of three bidders $(N=2)$, and the dotted line represents the case of five bidders $(N=4)$. The solid line provides a comparison benchmark when the firm does not have an all-pay auction and sells through a fixed list price channel only, in which case the expected profit is $\pi_{M}=p_{1}\left(1-F_{V}\left(p_{1}\right)\right)=p_{1}(1-$ $\left.p_{1}\right)$. We see that as the number of bidders increases, the profit function gets closer to the setting with only a fixed list price. From (8), we see that the asymptotic limit in $\mathrm{N}$ is the revenue from a fixed list price with no competing all-pay channel. Note too that for all cases, the optimal price $p_{1}^{*}$ that 
maximizes the firm's expected profit is $1 / 2$. We formally confirm this result in the following proposition.

Proposition 3. If there is only one firm operating both the fixed list price store and the all-pay auction channel, and bidders with valuation drawn from $\mathrm{U}[0,1]$ follow the strategies given in Lemmas 1 and 2 for the first-price scenario or Lemmas 3 and 4 for the second-price scenario, then the optimal price that maximizes expected revenue is $\mathrm{p}_{1}^{*}=1 / 2$.

Another thing to note in graph A of Fig. 5 is that for 'high' prices it seems that the firm is better off with the added channel, while for 'low' prices, the seller is better off with just the fixed list price sales channel. Comparing the expected revenue Eq. (8) with the expected revenue for a firm with only a fixed list price channel $\left(\pi_{M}\right)$, we can derive a threshold in $p_{1}$ for when the firm is better off with the added all-pay auction channel. This is result summarized in the following proposition.

Proposition 4. If there are $N+1$ bidders with valuation drawn from $\mathrm{U}[0,1]$ who follow the strategies given in Lemmas 1 and 2 for the first-price scenario or Lemmas 3 and 4 for the second-price scenario, and $p_{1} \gg \frac{N+2}{2(N+1)}$, then the firm's expected revenue (per bidder) is higher with the added all-pay auction than with just a fixed list price sales channel.

Thus, while the addition of an all-pay auction in the presence of optimally set prices decreases firm revenue (since it provides a bidder surplus), this loss decreases with an increased number of bidders and actually becomes a gain if the firm has sub-optimally set prices too high. We can also see that the threshold provided in Proposition 4 asymptotically approaches 0.5 as $N$ increases.

Note that although the expected total revenue is the same with or without the added $p_{2}$ post-bidding option, and regardless of the auction format, the distributions of the final auction price and total revenue are drastically different. From Fig. 3 , we observed that while $p_{2}$ does not affect the upper bound on bids in a first-price setting, it does so in a second-price setting. It therefore follows that the distributions of the final auction price and total revenue for the two auction formats and the two post-bidding options should display differences. Illustrations based on simulation results are shown in Fig. 6 . The box-plots are based on a simulation model for the single-firm scenario with four bidders, $V \sim \mathrm{U}[0,1], \mathrm{p}_{1}=.50, \mathrm{p}_{2}=.70, \mathrm{v}^{+}=: 76$ and $\mathrm{v}^{-}=.71$.

The box-plots are generated from 5000 iterations of randomly drawing four valuations and deriving the associated bids based on Lemmas 1-4 for the first- and second-price auction format, respectively. The box-plots in panel A represent the final auction price in the first-price (two left) and second-price (two right) (i.e., the highest and second highest bid, respectively). We observe that the inter-quartile range is larger when bidders have the added option to purchase at $p_{2}$. In particular, for the second-price auction format, the inter-quartile range is more than twice as large with the added $p_{2}$ option than it is with just the $p_{1}$. Furthermore, as evident from the graphs in Fig. 3 , we observe that in a first-price setting, the final auction price is bounded by $p_{1}$ (with or without the $p_{2}$ option), while in a second-price setting with the $p_{2}$ option, the final auction price is bounded by $p_{2}$; without the $p_{2}$, the final auction price is unbounded.

The box-plots in panel B of Fig. 6 display the total revenue for a single firm under five scenarios: fixed list price only at $p_{1}$ (leftmost box-plot), first-price all-pay with and without $p_{2}$ option 
(second and third from left), and second-price all-pay auction with and without $p_{2}$ option (two rightmost). We can observe that the inter-quartile range for a given auction format and the two postbidding options are almost identical. In other words, adding the $p_{2}$ options does not drastically affect the inter-quartile range and in fact, for the first-price scenario, the distributions are almost identical. For the second-price scenario with the $p_{2}$ option, the total revenue is, of course, bounded at $4 \times p_{2}=2.8$, while without $p_{2}$, the total revenue is (theoretically) unbounded. We also note the comparison to the scenario with a fixed list price channel only. We see that while the first-price scenario is quite close in distribution to the fixed list price only scenario, the inter-quartile range in the second-price scenario is almost twice.

Next, we illustrate the expected revenue for the dual firms, dual channels system. If the bidders' valuations are drawn from $U[0,1]$, then the seller's expected revenue function (4) becomes

$$
\pi_{r}=\frac{p_{1}^{N+2}}{N+1}+p_{1}\left(1-p_{1}\right)
$$

and the all-pay auctioneer's expected net revenue function (7) becomes

$$
\pi_{a p}=\frac{p_{1}^{N+1}}{N+1}\left(\frac{N p_{1}}{N+2}-1\right) .
$$

As we observed above, the seller's expected profit is always positive, while the auctioneer's expected net revenue is always negative (since $\left.N p_{1} /(N+2)<1\right)$. The seller would naturally want to set the optimal price $p_{1}^{*}$ that maximizes (9). However, unlike the scenario when the seller also operates the all-pay auction channel, the optimal price is not necessarily $1 / 2$. In fact, there is no closed-form solution for (9) since the function depends on the number of bidders through the $N+2$ exponent. Numerical illustrations of the expected profit functions (9) and (10) are provided in graph B of Fig. 5. The horizontal axis represents the fixed list price $p_{1}$, as set by the seller, while the vertical axis represents the expected revenue (per bidder) for the seller (top) and auctioneer (bottom). The dashed, dotted and solid lines represent the case with three, five, and nine bidders respectively (i.e., the top and bottom curves represent Eqs. (9) and (10), respectively, for different number of bidders). As anticipated, we see that the auctioneer always incurs an expected loss, and that the loss increases with the list price $p_{1}$ and decreases with the number of bidders. Further, we see that the seller's expected revenue is always positive and that, depending on the number of bidders, the optimal price $\mathrm{pH}$ changes. Note too that the sum of the seller's and auctioneer's expected revenue is 
equal to the expected revenue for the case with a single firm operating both channels, and that the asymptotic limit in $\mathrm{N}$ is the single firm operating a fixed list price only.

\section{Conclusion}

Auctions are an integral part of human commercial and social interaction. They were used in the ancient bazaars, and they are still used extensively in today's modern technology-driven markets. Given the importance and prevalence of auctions, it is not surprising to see a vast body of theoretical and empirical research developing around them. However, it is surprising that relatively little of this research has focused on understanding the implications of auctions in the presence of other commercial sales channels. Most bidders who are considering bidding for an item have external options to consider. This condition is not restricted solely to bidders bidding in, for instance, an online auction for the latest smartphone, but also to private collectors attending exclusive art auctions, billion-dollar telecom companies participating in official radio frequency spectrum auctions, or interest groups pursuing various lobbying activities. The objective of this paper has been to further our understanding of auctions in the presence of other competing sales channels.

Specifically, we analyzed the interaction between an all-pay auction and a fixed list-price store, and we derived: (1) equilibrium bidding and buying behaviors of the bidders, and (2) optimal list prices.

A novel contribution of our paper derives from the fact that we have extended the general auction framework to offer non-winning bidders an opportunity to use their sunk bid as a credit towards purchasing the item directly from the auctioneer. The 'buy-it-now' prices offered by online penny auctions represent a direct application of this framework. Most penny auction sites provide non-winning bidders with an opportunity to purchase the item directly at a fixed price, using their sunk bidding cost as credit. Another application of this extended framework could include situations where non-winning R\&D projects or lobbying activities ex post have options of other rewards from the 'auctioneer' (company or political party) - for example, patent applications or political concession to the interest group. The extension to having a credit-based post-bidding option provides further competition to the seller since this provision allows the auctioneer to also compete on quantity. In other words, although a seller might not have much concern for an auctioneer that is hosting a singleitem auction, they would need to be aware of an auctioneer that provides both auction and fixed list price opportunities for bidders. Through our private communication with penny auction sites, and as a result of anecdotal observation, we note that many penny auction websites are striving to establish themselves as permanent online stores with the auction option serving as just one of several sales mechanisms.

Our general conclusion points out that the presence of an auction channel competing with a store provides consumers with a positive expected surplus. The consumer surplus comes at the expense of a negative expected profit for the auctioneer. Consistent with our results, we highlight that the first entrant and dominant player, swoopo.com, filed for bankruptcy in March 2011 (Oswold, 2011) and that the specialized hotel and resort penny auction website offandaway.com is also no longer in operation. This reality stand in sharp contrast to both public perception and academic articles that portray penny auctions as commercial blockbusters; however, we would argue that not only are our results more reasonable, but they are also in line with what one could expect. That is, it would seem unreasonable that penny auction websites could be sustainable based on a business model where consumers derive a negative value or, to quote Myerson (1991): 
'If a theory [business model] predicts that some individuals will be systematically fooled or led into making costly mistakes, then this theory [business model] will tend to lose its validity when these individuals learn (from experience or from a published version of the theory [business model] itself) to better understand this situation.' (pg.5).

Finally, within today's e-marketplace, additional applications of all-pay auctions may develop. In the early dot-com period, many different auction formats existed (e.g., first vs. second price, single- vs. multi-item, fixed vs. variable end-time, etc). Therefore, we may witness online penny auctions experimenting with alternative versions of all-pay auctions. Furthermore, similar to the way that second-price auctions are used in online ad-space bidding, additional innovative online applications of all-pay auctions might arise as well. We therefore hope our models and results will provide a fruitful basis for researchers and practitioners alike.

\section{Appendix A. Proofs of results}

Proof Lemmas 1 and 2 - Let $b_{v}$ be the bid and $\emptyset_{v}$ be the expected surplus for a bidder with valuation $v$ who bids according to Lemmas 1 and 2 . There are three cases to consider: (I) $v \ll p_{1}$, (II) $p_{1}<v \ll v^{-}$, and (III) $v^{+}<v$.

Case I: $v \ll p_{1}$. From Auction Theory that he has no incentive to place a bid $b_{v}$ for $v^{\prime} \ll p_{1}$ and $v^{\prime} \neq v$ Krishna $\left(2002\right.$, p. 32). Need to show that he also has no incentive to try and place a bid $b_{v}$ for $v^{\prime}>p_{1}$. Since $\emptyset_{v} \ll \emptyset_{v^{\prime}}$ for $v \ll v^{\prime} 6 p_{1}$ we only need to show that a bidder with valuation $p_{1}$ has no incentive to bid $b_{v}$ for $v^{\prime}>p_{1}$. Proof by contradiction. Let $v^{\prime}>p_{1}$, then show the following is false,

$$
\phi_{p_{1}}<\rho_{v^{\prime}}\left(p_{1}-b_{v^{\prime}}\right)+\left(1-\rho_{v^{\prime}}\right) \max \left\{p_{1}-p_{2},-b_{v^{\prime}}\right\}
$$

The above inequality is either

$$
\begin{aligned}
& \phi_{p_{1}}<\rho_{v^{\prime}}\left(p_{1}-b_{v^{\prime}}\right)-\left(1-\rho_{v^{\prime}}\right) b_{v^{\prime}} \\
& \phi_{p_{1}}<\rho_{v^{\prime}} p_{1}-b_{v^{\prime}} \\
& b_{v^{\prime}}<\rho_{v^{\prime}} p_{1}-\phi_{p_{1}}
\end{aligned}
$$

or

$$
\begin{aligned}
& \phi_{p_{1}}<\rho_{v^{\prime}}\left(p_{1}-b_{v^{\prime}}\right)+\left(1-\rho_{v^{\prime}}\right)\left(p_{1}-p_{2}\right) \\
& \phi_{p_{1}}<p_{1}-\rho_{v^{\prime}} b_{v^{\prime}}-\left(1-\rho_{v^{\prime}}\right) p_{2} \\
& \rho_{v^{\prime}} b_{v^{\prime}}<p_{1}-\left(1-\rho_{v^{\prime}}\right) p_{2}-\phi_{p_{1}} \\
& b_{v^{\prime}}<\left(p_{1}-\left(1-\rho_{v^{\prime}}\right) p_{2}-\phi_{p_{1}}\right) / \rho_{v^{\prime}}
\end{aligned}
$$

Case II: $\mathrm{p}_{1}<\mathrm{v} \ll \mathrm{v}^{+}$. First we show a bidder with $\mathrm{p}_{1}<\mathrm{v} \ll \mathrm{v}^{+}$has no incentive to bid ${ }_{b^{\prime}}$ for $\mathrm{v}$ $\ll p_{1}$. Proof by contradiction. Since bv $+\mathrm{p} 16 p_{2}$ for $v 6 p_{1}$, show the following is false,

$$
\phi_{v}<\rho_{v^{\prime}}\left(v-b_{v^{\prime}}\right)+\left(1-\rho_{v^{\prime}}\right)\left(v-p_{1}-b_{v^{\prime}}\right)
$$


The above inequality is either

$$
\begin{aligned}
& \rho_{v}\left(v-b_{v}\right)+\left(1-\rho_{v}\right)\left(v-p_{1}-b_{v}\right)<\rho_{v^{\prime}}\left(v-b_{v^{\prime}}\right) \\
& \quad+\left(1-\rho_{v^{\prime}}\right)\left(v-p_{1}-b_{v^{\prime}}\right)-b_{v}-\left(1-\rho_{v}\right) p_{1}<-b_{v^{\prime}}-\left(1-\rho_{v^{\prime}}\right) p_{1} \\
& b_{v}+\left(1-\rho_{v}\right) p_{1}>b_{v^{\prime}}+\left(1-\rho_{v^{\prime}}\right) p_{1} \\
& \rho_{v} p_{1}-\phi_{p_{1}}+\left(1-\rho_{v}\right) p_{1}>\rho_{v^{\prime}} \mathrm{E}\left[V_{(1)} \mid V_{(1)}<v^{\prime}\right]+\left(1-\rho_{v^{\prime}}\right) p_{1} \\
& \quad-\rho_{p_{1}}\left(p_{1}-\mathrm{E}\left[V_{(1)} \mid V_{(1)}<p_{1}\right]\right)>\rho_{v^{\prime}}\left(\mathrm{E}\left[V_{(1)} \mid V_{(1)}<v^{\prime}\right]-p_{1}\right) \\
& \rho_{p_{1}}\left(p_{1}-\mathrm{E}\left[V_{(1)} \mid V_{(1)}<p_{1}\right]\right)<\rho_{v^{\prime}}\left(p_{1}-\mathrm{E}\left[V_{(1)} \mid V_{(1)}<v^{\prime}\right]\right)
\end{aligned}
$$

or

$$
\begin{aligned}
& \rho_{v}\left(v-b_{v}\right)+\left(1-\rho_{v}\right)\left(v-p_{2}\right)<\rho_{v^{\prime}}\left(v-b_{v^{\prime}}\right)+\left(1-\rho_{v^{\prime}}\right)\left(v-p_{1}-b_{v^{\prime}}\right) \\
& \quad-\rho_{v} b_{v}-\left(1-\rho_{v}\right) p_{2}<-b_{v^{\prime}}-\left(1-\rho_{v^{\prime}}\right) p_{1} \\
& \rho_{v} b_{v}+\left(1-\rho_{v}\right) p_{2}>b_{v^{\prime}}+\left(1-\rho_{v^{\prime}}\right) p_{1} \\
& \rho_{v}\left(p_{1}-\left(1-\rho_{v}\right) p_{2}-\phi_{p_{1}}\right) / \rho_{v}+\left(1-\rho_{v}\right) p_{2}>\rho_{v^{\prime}} \mathrm{E}\left[V_{(1)} \mid V_{(1)}<v^{\prime}\right] \\
& \quad+\left(1-\rho_{v^{\prime}}\right) p_{1}-\phi_{p_{1}}>\rho_{v^{\prime}}\left(\mathrm{E}\left[V_{(1)} \mid V_{(1)}<v^{\prime}\right]-p_{1}\right) \\
& \rho_{p_{1}}\left(p_{1}-\mathrm{E}\left[V_{(1)} \mid V_{(1)}<p_{1}\right]\right)<\rho_{v^{\prime}}\left(p_{1}-\mathrm{E}\left[V_{(1)} \mid V_{(1)}<v^{\prime}\right]\right)
\end{aligned}
$$

where the last condition for both cases is false as the right hand side is maximized at $v^{\prime}=p_{1}$.

Next we show a bidder with $p_{1}<v^{\prime} \ll v+$ has no incentive to bid $b_{v^{\prime}}$ for $p_{1}<v^{\prime} \ll v^{+}, v^{\prime} \neq v$.

Proof by contradiction. We show the following is false,

$$
\phi_{v}<\rho_{v^{\prime}}\left(v-b_{v^{\prime}}\right)+\left(1-\rho_{v^{\prime}}\right) \max \left\{v-p_{2}, v-p_{1}-b_{v^{\prime}}\right\}
$$

The above inequality is either

$$
\begin{aligned}
& \rho_{v}\left(v-b_{v}\right)+\left(1-\rho_{v}\right)\left(v-p_{1}-b_{v}\right)<\rho_{v^{\prime}}\left(v-b_{v^{\prime}}\right)+\left(1-\rho_{v^{\prime}}\right)\left(v-p_{1}-b_{v^{\prime}}\right) \\
& \quad-b_{v}-\left(1-\rho_{v}\right) p_{1}<-b_{v^{\prime}}-\left(1-\rho_{v^{\prime}}\right) p_{1} \\
& \rho_{v} p_{1}-\phi_{p_{1}}+\left(1-\rho_{v}\right) p_{1}>\rho_{v^{\prime}} p_{1}-\phi_{p_{1}}+\left(1-\rho_{v^{\prime}}\right) p_{1} \\
& p_{1}-\phi_{p_{1}}>p_{1}-\phi_{p_{1}}
\end{aligned}
$$

or 


$$
\begin{aligned}
& \rho_{v}\left(v-b_{v}\right)+\left(1-\rho_{v}\right)\left(v-p_{1}-b_{v}\right)<\rho_{v^{\prime}}\left(v-b_{v^{\prime}}\right)+\left(1-\rho_{v^{\prime}}\right)\left(v-p_{2}\right) \\
& \quad-b_{v}-\left(1-\rho_{v}\right) p_{1}<-\rho_{v^{\prime}} b_{v^{\prime}}-\left(1-\rho_{v^{\prime}}\right) p_{2}-\rho_{v} p_{1}+\phi_{p_{1}} \\
& \quad-\left(1-r h o_{v}\right) p_{1}<-\rho_{v^{\prime}}\left(\rho_{v^{\prime}} p_{1}-\phi_{p_{1}}\right)-\left(1-\rho_{v^{\prime}}\right) p_{2} \\
& \left(1-\rho_{v^{\prime}}\right) p_{2}-p_{1}+\phi_{p_{1}}<-\rho_{v^{\prime}}\left(\rho_{v^{\prime}} p_{1}-\phi_{p_{1}}\right) \\
& \left(1-\rho_{v^{\prime}}\right) p_{2}-p_{1}+\left(1-\rho_{v^{\prime}}\right) \phi_{p_{1}}-\left(1-\rho_{v^{\prime}}\right)\left(1+\rho_{v^{\prime}}\right) p_{1}<0 \\
& \left(p_{2}-p_{1}+\phi_{p_{1}}\right) / p_{1}<\rho_{v^{\prime}}
\end{aligned}
$$

The last condition in the first case is clearly false, and the last condition in the second case is false by definition of $\mathrm{v}^{+}$.

Remain to show that a bidder with $\mathrm{p}_{1}<v \ll v^{+}$has no incentive to bid $b_{v}$ for $v^{\prime}>v^{+}$. Proof by contradiction. Let $v^{\prime}>v^{+}$, then show the following is false,

$$
\phi_{v}<\rho_{v^{\prime}}\left(v-b_{v^{\prime}}\right)+\left(1-\rho_{v^{\prime}}\right) \max \left\{v-p_{2}, v-p_{1}-b_{v^{\prime}}\right\}
$$

The above inequality is either

$$
\begin{aligned}
& \rho_{v}\left(v-b_{v}\right)+\left(1-\rho_{v}\right)\left(v-p_{1}-b_{v}\right)<\rho_{v^{\prime}}\left(v-b_{v^{\prime}}\right)+\left(1-\rho_{v^{\prime}}\right)\left(v-p_{2}\right) \\
& v-b_{v}-\left(1-\rho_{v}\right) p_{1}<v-\rho_{v^{\prime}} b_{v^{\prime}}-\left(1-\rho_{v^{\prime}}\right) p_{2}-\rho_{v} p_{1}+\phi_{p_{1}} \\
& \quad-\left(1-\rho_{v}\right) p_{1}<-\rho_{v^{\prime}}\left(p_{1}-\left(1-\rho_{v^{\prime}}\right) p_{2}-\phi_{p_{1}}\right) / \rho_{v^{\prime}}-\left(1-\rho_{v^{\prime}}\right) p_{2} \phi_{p_{1}}<\phi_{p_{1}}
\end{aligned}
$$

or

$$
\begin{aligned}
& \rho_{v}\left(v-b_{v}\right)+\left(1-\rho_{v}\right)\left(v-p_{1}-b_{v}\right)<\rho_{v^{\prime}}\left(v-b_{v^{\prime}}\right)+\left(1-\rho_{v^{\prime}}\right)\left(v-p_{1}-b_{v^{\prime}}\right) \\
& v-b_{v}-\left(1-\rho_{v}\right) p_{1}<v-b_{v^{\prime}}-\left(1-\rho_{v^{\prime}}\right) p_{1} \\
& b_{v^{\prime}}-b_{v}-\left(\rho_{v^{\prime}}-\rho_{v}\right) p_{1}<0 \\
& \left(p_{1}-\left(1-\rho_{v^{\prime}}\right) p_{2}-\phi_{p_{1}}\right) / \rho_{v^{\prime}}-\rho_{v} p_{1}+\phi_{p_{1}}-\left(\rho_{v^{\prime}}-\rho_{v}\right) p_{1}<0 \\
& \left(1-\rho_{v^{\prime}}\right)\left(1+\rho_{v^{\prime}}\right) p_{1}-\left(1-\rho_{v^{\prime}}\right) p_{2}-\left(1-\rho_{v^{\prime}}\right) \phi_{p_{1}}<0 \\
& \left(1+\rho_{v^{\prime}}\right) p_{1}-p_{2}-\phi_{p_{1}}<0 \\
& p_{1}-p_{2}-\phi_{p_{1}}<-\rho_{v^{\prime}} p_{1}\left(p_{2}-p_{1}+\phi_{p_{1}}\right) / p_{1}>\rho_{v^{\prime}}
\end{aligned}
$$

The last condition in the first case is clearly false, and the last condition in the second case is also false since $\left(p_{2}-p_{1}+\emptyset_{P_{1}}\right) / p_{1}<P_{v^{\prime}}$ for all $v^{\prime}>v^{+}$by definition of $v^{+}$.

Case III: $v^{+}<v$. The proof for showing a bidder has no incentive to bid $b_{v^{\prime}}$ for $v^{\prime} \ll P_{1}$ follows the exact same logic as Case II above. Next we show that $v>v+$ has no incentive to bid $b_{v^{\prime}}$ for $p_{1}<v^{\prime}$ $\ll v^{+}$. Proof by contradiction. Let $p_{1}<v^{\prime} \ll v^{+}$, then show the following is false, 


$$
\phi_{v}<\rho_{v^{\prime}}\left(v-b_{v^{\prime}}\right)+\left(1-\rho_{v^{\prime}}\right) \max \left\{v-p_{2}, v-p_{1}-b_{v^{\prime}}\right\}
$$

The above inequality is either

$$
\begin{aligned}
& \rho_{v}\left(v-b_{v}\right)+\left(1-\rho_{v}\right)\left(v-p_{2}\right)<\rho_{v^{\prime}}\left(v-b_{v^{\prime}}\right)+\left(1-\rho_{v^{\prime}}\right)\left(v-p_{2}\right) \\
& v-\rho_{v} b_{v}-\left(1-\rho_{v}\right) p_{2}<v-\rho_{v^{\prime}} b_{v^{\prime}}-\left(1-\rho_{v^{\prime}}\right) p_{2} \\
& \quad-\rho_{v}\left(p_{1}-\left(1-\rho_{v}\right) p_{2}-\phi_{p_{1}}\right) / \rho_{v}-\left(1-\rho_{v}\right) p_{2}<-\rho_{v^{\prime}}\left(\rho_{v^{\prime}} p_{1}-\phi_{p_{1}}\right) \\
& \quad-\left(1-\rho_{v^{\prime}}\right) p_{2}-p_{1}+\phi_{p_{1}}<-\rho_{v^{\prime}}\left(\rho_{v^{\prime}} p_{1}-\phi_{p_{1}}\right)-\left(1-\rho_{v^{\prime}}\right) p_{2} \\
& 0<\left(1-\rho_{v^{\prime}}\right)\left(1+\rho_{v^{\prime}}\right) p_{1}-\left(1-\rho_{v^{\prime}}\right) \phi_{p_{1}}-\left(1-\rho_{v^{\prime}}\right) p_{2} \\
& 0<\left(1+\rho_{v^{\prime}}\right) p_{1}-\phi_{p_{1}}-p_{2}-\rho_{v^{\prime}} p_{1}<p_{1}-\phi_{p_{1}}-p_{2} \rho_{v^{\prime}}>\left(p_{2}-p_{1}+\phi_{p_{1}}\right) / p_{1}
\end{aligned}
$$

or

$$
\begin{aligned}
& \rho_{v}\left(v-b_{v}\right)+\left(1-\rho_{v}\right)\left(v-p_{2}\right)<\rho_{v^{\prime}}\left(v-b_{v^{\prime}}\right)+\left(1-\rho_{v^{\prime}}\right)\left(v-p_{1}-b_{v^{\prime}}\right) \\
& v-\rho_{v} b_{v}-\left(1-\rho_{v}\right) p_{2}<v-b_{v^{\prime}}-\left(1-\rho_{v^{\prime}}\right) p_{1}-\left(p_{1}-\left(1-\rho_{v}\right) p_{2}-\phi_{p_{1}}\right) \\
& \quad-\left(1-\rho_{v}\right) p_{2}<-\rho_{v^{\prime}} p_{1}+\phi_{p_{1}}-\left(1-\rho_{v^{\prime}}\right) p_{1} \phi_{p_{1}}<\phi_{p_{1}}
\end{aligned}
$$

The last condition in both cases are false for the same reason as before, i.e. $\left(p_{2}-p_{1}+\emptyset_{\mathrm{P}_{1}}\right) / p_{1}>P_{v^{\prime}}$ for all $p_{1}\left\langle v^{\prime}\left\langle v^{+}\right.\right.$by definition of $v^{+}$, and clearly $\emptyset_{\mathrm{P}_{1}} \gg \emptyset_{\mathrm{P} 1}$.

Remain to show that a bidder with $v^{+}<v$ has no incentive to bid $b_{v^{\prime}}$ for $v^{+}<v^{\prime}, v^{\prime} \neq v$. Proof by contradiction. Let $v+<v^{\prime}$, then show the following is false,

$$
\phi_{v}<\rho_{v^{\prime}}\left(v-b_{v^{\prime}}\right)+\left(1-\rho_{v^{\prime}}\right) \max \left\{v-p_{2}, v-p_{1}-b_{v^{\prime}}\right\}
$$

The above inequality is either

$$
\begin{aligned}
& \rho_{v}\left(v-b_{v}\right)+\left(1-\rho_{v}\right)\left(v-p_{2}\right)<\rho_{v^{\prime}}\left(v-b_{v^{\prime}}\right)+\left(1-\rho_{v^{\prime}}\right)\left(v-p_{2}\right) \\
& v-\rho_{\nu} b_{v}-\left(1-\rho_{v}\right) p_{2}<v-\rho_{v^{\prime}} b_{v^{\prime}}-\left(1-\rho_{v^{\prime}}\right) p_{2}-\left(p_{1}-\left(1-\rho_{v}\right) p_{2}\right. \\
& \left.\quad-\phi_{p_{1}}\right)-\left(1-\rho_{v}\right) p_{2}<-\left(p_{1}-\left(1-\rho_{v^{\prime}}\right) p_{2}-\phi_{p_{1}}\right)-\left(1-\rho_{v^{\prime}}\right) p_{2} \\
& \quad-p_{1}+\phi_{p_{1}}<-p_{1}+\phi_{p_{1}}
\end{aligned}
$$

or 


$$
\begin{aligned}
& \rho_{v}\left(v-b_{v}\right)+\left(1-\rho_{v}\right)\left(v-p_{2}\right)<\rho_{v^{\prime}}\left(v-b_{v^{\prime}}\right)+\left(1-\rho_{v^{\prime}}\right)\left(v-p_{1}-b_{v^{\prime}}\right) \\
& v-\rho_{\nu} b_{v}-\left(1-\rho_{v}\right) p_{2}<v-b_{v^{\prime}}-\left(1-\rho_{v^{\prime}}\right) p_{1}-\left(p_{1}-\left(1-\rho_{v}\right) p_{2}-\phi_{p_{1}}\right) \\
& -\left(1-\rho_{v}\right) p_{2}<-b_{v^{\prime}}-\left(1-\rho_{v^{\prime}}\right) p_{1} \rho_{v^{\prime}} p_{1}-\phi_{p_{1}}>b_{v^{\prime}}
\end{aligned}
$$

The last condition for the first case is cleary false, and the last condition of the second case is false for all $v>v^{\prime}$ (by definition of $v^{\prime}$ ).

Proof Corollary 1 - If $\mathrm{p}_{2} \geq 2 \mathrm{p}_{1}$ then $\left(\mathrm{p}_{2}-\mathrm{p}_{1}+\emptyset_{\mathrm{P} 1}\right) / \mathrm{p}_{1}>1$, and hence $\mathrm{v}^{+}=\bar{v}$.

Proof Lemmas 3 and 4 - Let $\emptyset_{v}$ be the expected surplus for a bidder with valuation $v$ who follows the bidding/buying strategy specified in the Lemmas, and let $\emptyset_{v}\left(b^{\prime}\right)$ be the expected surplus of a bidder with valuation vbut who bids $b^{\prime}=b_{v^{\prime}}$ (i.e. the expected surplus of a bidder with valuation $v$ that bids as though their valuation was v'). From the Revenue Equivalence Theorem (cf. Krishna, 2002, chap. 3 ), and based on results from the First-Price All-Pay Auction (Lemmas 1 and 2), we have (1) $\emptyset_{v}=P_{v}(v-$ $\left.\mathrm{f}\left[\mathrm{V}_{(\mathrm{II})} \mid V_{(\mathrm{I})}<\mathrm{v}\right]\right)$, for $\mathrm{v} \ll \mathrm{P}_{1}$, and (2) $\emptyset_{v}=\mathrm{v}-\mathrm{p}_{1}+\emptyset_{\mathrm{P} 1}$, for $\mathrm{v}>\mathrm{p}_{1}$. There are three cases to consider: (I) $\mathrm{v}$ $\ll \mathrm{P}_{1}$, (II) $\mathrm{P}_{1}<\mathrm{v} \ll v^{-}$, and (III) $\mathrm{v}^{-}<\mathrm{v}$.

Case I: $v \ll P_{1}$. From standard auction theory results (cf. Milgrom \& Weber (1985), Krishna \& Morgan (1997)) we know that a bidder with valuation $v$ has no incentive of bidding $b^{\prime}=b_{v^{\prime}}$, for $v^{\prime} \neq v$, and $v^{\prime}$ $\ll p_{1}$. Need to establish that the bidder also has no incentive of bidding $b^{\prime}=b_{v^{\prime}}$ for $v^{\prime}>p_{1}$. First consider when $p_{1}<v^{\prime} \ll v^{-}$, with $v^{-}$defined by Lemma 4 . We show that if bidder with valuation $v$ bids $\mathrm{b}$ and derives expected surplus $\emptyset_{\mathrm{v}}\left(\mathrm{b}^{\prime}\right)$, then $\emptyset_{\mathrm{v}}\left(\mathrm{b}^{\prime}\right) \ll \emptyset_{\mathrm{v}}$. First note that,

$$
\begin{aligned}
\phi_{v}\left(b^{\prime}\right) & =\phi_{v^{\prime}}-\rho_{v^{\prime}} v^{\prime}+\rho_{v^{\prime}} v-\left(1-\rho_{v^{\prime}}\right)\left(v^{\prime}-p_{1}\right) \\
& =v^{\prime}-p_{1}+\phi_{p_{1}}-\rho_{v^{\prime}} v^{\prime}+\rho_{v^{\prime}} v-\left(1-\rho_{v^{\prime}}\right)\left(v^{\prime}-p_{1}\right) \\
& =\phi_{p_{1}}+\rho_{v^{\prime}}\left(v-v^{\prime}\right)+\rho_{v^{\prime}}\left(v^{\prime}-p_{1}\right) \\
& =\phi_{p_{1}}-\rho_{v^{\prime}}\left(p_{1}-v\right)
\end{aligned}
$$

Second note that since $\emptyset_{\mathrm{v}} \gg \emptyset_{\mathrm{v}}\left(\mathrm{b}_{\mathrm{P} 1}\right)$ (due to equilibrium bidding strategy), we have $\emptyset_{\mathrm{v}} \gg \emptyset_{\mathrm{vP} 1}\left(p_{1}-\mathrm{v}\right)$. Therefore if $\emptyset_{\mathrm{v}}\left(\mathrm{b}^{\prime}\right)>\emptyset_{\mathrm{v}^{\prime}}$ then

$$
\begin{aligned}
& \phi_{p_{1}}-\rho_{v^{\prime}}\left(p_{1}-v\right)>\phi_{p_{1}}-\rho_{p_{1}}\left(p_{1}-v\right) \\
& \rho_{v^{\prime}}\left(p_{1}-v\right)<\rho_{p_{1}}\left(p_{1}-v\right) \\
& \rho_{v^{\prime}}<\rho_{p_{1}}
\end{aligned}
$$


The last condition is false since $P_{v}$ is increasing in $v$ and we are assuming $v^{\prime}>P_{1}$. Therefore bidders with $v \ll P_{1}$ have no incentive to bid $b^{\prime}=b_{v}{ }^{\prime}$ for $P_{1}<v^{\prime} \ll v^{\prime}$.

Next show that the bidder with valuation $v \ll P_{1}$, also has no incentive to bid $b^{\prime}=b_{v}$, for $v^{-}<$ $v^{\prime}$. First, note that there is no incentive for bidding $b^{\prime}>P_{2}$, since that will never result in any additional benefit over bidding $b^{\prime}=P_{2}$. Second,

$$
\phi_{v}\left(b^{\prime}\right)=\phi_{v^{\prime}}-v^{\prime}+v=v^{\prime}-p_{1}+\phi_{p_{1}}-v^{\prime}+v=v-p_{1}+\phi_{p_{1}}
$$

If $\phi_{v}\left(b^{\prime}\right)>\phi_{v}$ then,

$$
v-p_{1}+\phi_{p_{1}}>\phi_{v} \Rightarrow v-\phi_{v}>p_{1}-\phi_{p_{1}}
$$

where the last inequality is false for all $v<P_{1}$, since $\emptyset_{v}$ is convex. Therefore bidders with $v \ll P_{1}$ also have no incentive to bid $b^{\prime}=b_{v^{\prime}}$ for $v^{-}<v^{\prime}$.

Case II: $P_{1}<v \ll v$. The notations $b_{v}$ and $b(v)$ are used interchangeable to represent the bidding strategy for a bidder with valuation $\mathrm{v}$, and $\mathrm{b}^{-1}(\beta)$ is used to represent the inverse bidding function for a bid $\beta$. We let $\mathrm{G}(\mathrm{x})=P_{\mathrm{x}}=\operatorname{Pr}\left\{\mathrm{V}_{(1)}<\mathrm{x}\right\}=\left(F_{V}(\mathrm{x})\right)^{\mathrm{N}}$, and $\mathrm{g}(\mathrm{x})=\delta \mathrm{G}(\mathrm{x}) / \delta \mathrm{x}$, denote the cumulative and probability density function of $\mathrm{V}_{(1)}$ (the highest order statistics of the other $\mathrm{N}$ bidders' valuation). Note that bidders that lose the auction will always return to the retail store and buy the item at $\mathrm{P}_{1}$, therefore the expected surplus for a bidder with valuation $v$ that bids $\beta$ is given by,

$$
\begin{aligned}
\phi_{v}(\beta)= & \int_{\underline{v}}^{p_{1}}\left(v-b_{x}\right) g(x) d x+\int_{p_{1}}^{b^{-1}(\beta)}\left(v-b_{x}\right) g(x) d x \\
& +\left(v-p_{1}-\beta\right)\left[1-G\left(b^{-1}(\beta)\right)\right]
\end{aligned}
$$

where the $b_{x}$ are different for the two integrals and defined according to the Lemma 3. Maximizing (A.1) with respect to $\beta$ yields the first-order condition,

$$
\begin{aligned}
& {\left[v-b\left(b^{-1}(\beta)\right)\right] g\left(b^{-1}(\beta)\right) \frac{\delta b^{-1}(\beta)}{\delta \beta}-\left[1-G\left(b^{-1}(\beta)\right)\right]+\left(v-p_{1}-\beta\right)} \\
& -\frac{\delta G\left(b^{-1}(\beta)\right)}{\delta \beta}=0 \Rightarrow[v-\beta] g\left(b^{-1}(\beta)\right) \frac{\delta b^{-1}(\beta)}{\delta \beta}-\left[1-G\left(b^{-1}(\beta)\right)\right] \\
& -\left(v-p_{1}-\beta\right) g\left(b^{-1}(\beta)\right) \frac{\delta b^{-1}(\beta)}{\delta \beta}=0 \Rightarrow p_{1} g\left(b^{-1}(\beta)\right) \frac{\delta b^{-1}(\beta)}{\delta \beta} \\
& -\left[1-G\left(b^{-1}(\beta)\right)\right]=0 \Rightarrow p_{1} g\left(b^{-1}(\beta)\right) \frac{1}{\delta b\left(b^{-1}(\beta)\right) / \delta \beta} \\
& -\left[1-G\left(b^{-1}(\beta)\right)\right]=0
\end{aligned}
$$

at a symmetric equilibrium, $\beta=\mathrm{b}(\mathrm{v})$, which yields, 


$$
\frac{\delta b(v)}{\delta \beta}=\frac{p_{1} g(v)}{[1-G(v)]}
$$

and therefore,

$$
b(v)=b_{p_{1}}+\int_{p_{1}}^{v} p_{1} \lambda(x) d x
$$

Next, we show that a bidder with valuation $v$, with $P_{1}<v \ll v$, has no incentive to deviate and $b i d b^{\prime}=b_{v}{ }^{\prime}$ for $v^{\prime} \ll P_{1}$. Suppose a bidder with valuation $v$ bids $b^{\prime}$ and derives expected surplus $\emptyset_{v}\left(b^{\prime}\right)$, where,

$$
\phi_{v}\left(b^{\prime}\right)=\phi_{v^{\prime}}-\rho_{v^{\prime}} v^{\prime}+\rho_{v^{\prime}} v+\left(1-\rho_{v^{\prime}}\right)\left(v-p_{1}\right)
$$

if $\phi_{v}\left(b^{\prime}\right)>\phi_{v}$, then,

$$
\begin{gathered}
\phi_{v^{\prime}}-\rho_{v^{\prime}} v^{\prime}+\rho_{v^{\prime}} v+\left(1-\rho_{v^{\prime}}\right)\left(v-p_{1}\right)>v-p_{1}+\phi_{p_{1}} \\
\Rightarrow \phi_{v^{\prime}}-\rho_{v^{\prime}} v^{\prime}+\rho_{v^{\prime}} p_{1}>\phi_{p_{1}} \Rightarrow \phi_{v^{\prime}}\left(p_{1}\right)>\phi_{p_{1}}
\end{gathered}
$$

where if the last inequality holds then there is an incentive for bidders with valuation $\mathrm{P}_{1}$, to deviate from the equilibrium bidding strategy of a second-price all-pay auction. Which is a contradiction. Therefore bidders with $P_{1}<v \ll v^{-}$have no incentive to $b i d b^{\prime}=b_{v^{\prime}}$ for $v^{\prime} \ll P_{1}$.

Next show that the bidder with valuation $P_{1}<v 6 v^{-}$also have no incentive to bid $b^{\prime}=b_{v}$, for $v^{-}<v^{\prime}$. First, note that there is no incentive for bidding $b^{\prime}>P_{2}$ since that will never result in any additional benefit over bidding $b^{\prime}=P_{2}$. Second,

$$
\phi_{v}\left(b^{\prime}\right)=\phi_{v^{\prime}}-v^{\prime}+v=v^{\prime}-p_{1}+\phi_{p_{1}}-v^{\prime}+v=v-p_{1}+\phi_{p_{1}}
$$

and therefore trivially it is false that $\emptyset_{v}\left(b^{\prime}\right)>\emptyset_{v}$, and bidders with $P_{1}<v \ll v^{-}$have no incentive to bid $b^{\prime}=b_{v}{ }^{\prime}$ for $v^{-}<v^{\prime}$.

Case III: $v^{-}<v$. Note that $v^{-}$is the valuation such that $P_{1}+b_{v}=P_{2}$. Furthermore, as above, it should be fairly intuitive that given the other bidders follow the bidding strategy of Lemmas 3 and 4 there is no incentive to bid more than $\mathrm{P}_{2}$. Because if the bidder bids more than $\mathrm{P}_{2}$ then in the cases when the second highest valuation is less than $v^{-}$there is no additional gain, and in the case when the second highest valuation is more than $\mathrm{v}^{-}$(and that bidder bids $\mathrm{P}_{2}$ ) then regardless if the bidder win or lose the auction they still have to pay $P_{2}$. Remains to establish that with valuation $v$, with $v^{-}<v$, has no incentive to deviate and bid $b^{\prime}=b_{v}$, for $(a) v \ll P_{1}$, and $(b) P_{1}<v^{\prime} \ll v^{-}$. Where both cases follow the exact same argument and logic as for Case II above. Therefore, bidders with $v^{-}<v$ have no incentive to bid $b^{\prime}=b_{v}$, for $v^{\prime} \ll v^{\prime}$.

Proof Corollary 2 - If $\mathrm{P}_{2}=\mathrm{P}_{1}+\mathrm{b}_{\mathrm{P}_{1}}$, then $\mathrm{v}^{-}=\mathrm{P}_{1}$. 
Proof of Proposition 1 - If there is only one seller operating both the fixed list price store and the first-price all-pay auction, then the seller receives bids bv from bidders with valuations below $P_{1}$, either $b_{v}$ or $b_{v}+P_{1}$ for those with valuations between $P_{1}$ and $v^{+}$depending on whether the bidder wins or loses the auction, and similarly $b_{v}$ or $P_{2}$ from winners and losers with valuations above $v^{+}$. Therefore the seller's expected profit (per bidder) $\pi_{1 s t}$ is expressed as,

$$
\begin{aligned}
\pi_{1^{s t}}= & \int_{\underline{v}}^{p_{1}} b_{v} f(v) d v+\int_{p_{1}}^{v^{+}}\left[\rho_{v} b_{v}+\left(1-\rho_{v}\right)\left(p_{1}+b_{v}\right)\right] f(v) d v \\
& +\int_{v^{+}}^{\bar{v}}\left[\rho_{v} b_{v}+\left(1-\rho_{v}\right) p_{2}\right] f(v) d v \\
= & \int_{\underline{v}}^{p_{1}} b_{v} f(v) d v+\int_{p_{1}}^{v^{+}}\left[b_{v}+\left(1-\rho_{v}\right) p_{1}\right] f(v) d v \\
& +\int_{v^{+}}^{\bar{v}}\left[\rho_{v} b_{v}+\left(1-\rho_{v}\right) p_{2}\right] f(v) d v
\end{aligned}
$$

with $b_{v}$ and $v^{+}$defined in Lemmas 1 and 2 , this becomes,

$$
\begin{aligned}
\pi_{1^{s t}}= & \int_{\underline{v}}^{p_{1}} \rho_{v} E\left[V_{(1)} \mid V_{(1)}\right. \\
< & v] f(v) d v+\int_{p_{1}}^{v^{+}}\left[\rho_{v} p_{1}-\phi_{p_{1}}+\left(1-\rho_{v}\right) p_{1}\right] f(v) d v \\
& +\int_{v^{+}}^{\bar{v}}\left[\rho_{v}\left(p_{1}-\left(1-\rho_{v}\right) p_{2}-\phi_{p_{1}}\right) / \rho_{v}+\left(1-\rho_{v}\right) p_{2}\right] f(v) d v
\end{aligned}
$$

which after simplification becomes,

$$
\pi_{1^{s t}}=\int_{\underline{v}}^{p_{1}} \rho_{\nu} E\left[V_{(1)} \mid V_{(1)}<v\right] f(v) d v+\int_{p_{1}}^{\bar{v}}\left(p_{1}-\phi_{p_{1}}\right) f(v) d v
$$

with $\emptyset_{\mathrm{P} 1}=p_{\mathrm{p} 1}\left(\mathrm{p}_{1}-E\left[\mathrm{~V}_{(1)} \mid \mathrm{V}_{(1)}<\mathrm{p}_{1}\right]\right)$ the result holds for the first- price setting. By applying the revenue equivalence theorem, we have that $\pi_{2 n d}=\pi_{1 s t}$, and the result holds.

Proof of Proposition 2 - Using the same strategy as in the previous proposition, we start by considering the case for the first-price all-pay auction. Recall that both the winner of the first-price allpay auction as well as the losers with $v>v^{+}$receives an item from the all-pay auction channel. By substituting the bidding strategies from Lemmas 1 and 2, the expected profit (per bidder) for the allpay auctioneer becomes, 


$$
\begin{aligned}
\pi_{1^{s t} a p}= & \int_{\underline{v}}^{p_{1}}\left(b_{v}-\rho_{v} p_{1}\right) f(v) d v+\int_{p_{1}}^{v^{+}}\left(b_{v}-\rho_{v} p_{1}\right) f(v) d v \\
& +\int_{v^{+}}^{\bar{v}}\left(\rho_{v} b_{v}+\left(1-\rho_{v}\right) p_{2}-p_{1}\right) f(v) d v \\
= & \int_{\underline{v}}^{p_{1}} \rho_{v}\left(E\left[V_{(1)} \mid V_{(1)}<v\right]-p_{1}\right) f(v) d v-\phi_{p_{1}}\left(1-F_{V}\left(p_{1}\right)\right)
\end{aligned}
$$

Since $E\left[V_{(1) \mid} V_{(1)}<v\right] \ll P_{1}$ for all $v \ll P_{1}$, and $\emptyset_{P 1} \gg 0$ it follow that the first-price all-pay auctioneer's expected profit is always nega-tive (strictly speaking it is non-positive). By applying the revenue equivalence theorem, we have that $\pi_{2 n d a p}=\pi_{1 s t a p}$, and the result holds.

Proof Proposition 3 - The optimal price $p_{1}^{*}$ can be found by taking the derivative of (8) with respect to $\mathrm{p}_{1}$, i.e. by setting $\frac{\delta \pi}{\delta p 1}=0$,

$$
\begin{aligned}
\frac{\partial \pi}{\partial p_{1}} & =1-2 p_{1}+2 p_{1}^{N+1}-p_{1}^{N}=0 \Rightarrow\left(1-2 p_{1}\right)-p_{1}^{N}\left(1-2 p_{1}\right)=0 \\
& \Rightarrow\left(1-2 p_{1}\right)\left(1-p_{1}^{N}\right)=0 \Rightarrow p_{1}^{*}=\frac{1}{2}
\end{aligned}
$$

\section{Proof Proposition 4}

$$
\begin{aligned}
p_{1} & \geqslant \frac{N+2}{2(N+1)} \Rightarrow 2 p_{1}(N+1)-(N+2) \geqslant 0 \\
& \Rightarrow \frac{2 p_{1}(N+1)-(N+2)}{(N+2)(N+1)} \geqslant 0 \Rightarrow p_{1}^{N+1}\left(\frac{2 p_{1}}{N+2}-\frac{1}{N+1}\right) \geqslant 0 \\
& \Rightarrow p_{1}^{N+2} \frac{2}{N+2}-p_{1}^{N+1} \frac{1}{N+1} \geqslant 0 \\
& \Rightarrow p_{1}\left(1-p_{1}\right)+p_{1}^{N+2} \frac{2}{N+2}-p_{1}^{N+1} \frac{1}{N+1} \geqslant p_{1}\left(1-p_{1}\right)
\end{aligned}
$$

\section{References}

Anderson, S., Goeree, J., \& Holt, C. (1998). Rent seeking with bounded rationality: An analysis of the all-pay auction. Journal of Political Economy, 106, 828-853. Augenblick, N. (2011). Consumer and Producer Behavior in the Market for Penny Auctions: A Theoretical and Empirical Analysis, working paper. <faculty. haas.berkeley.edu/ned/Augenblick_JMP_Penny_Auction.pdf> (Accessed 09. 
05.14).

Baye, M., Kovenock, D., \& de Vries, C. (1993). Rigging the lobbying process: An application of the all-pay auction. American Economic Review, 83, 289-294.

Bishop, D., Cannings, C., \& Maynard Smith, J. (1978). The war of attrition with random rewards. Journal of Theoretical Biology, 74, 377-388.

BusinessWire, (2010). Law Firm Beckham \& Mandel Files Class Action Lawsuit Against QuiBids, LLC, article 2010-11-30. <http://www.businesswire.com/ news/home/20101130007096/en/Law-Firm-Beckham-Mandel-Files-Class-Action> (Accessed 09.05.14).

Byers, J., Mitzenmacher, M., Zervas, G. (2010). Information asymmetries in pay-perbid auctions. How Swoopo Makes Bank, working paper. <http://arxiv.org/ PS_cache/arxiv/pdf/1001/1001.0592v3.pdf> (Accessed 09.05.14).

Caldentey, R., \& Vulcano, G. (2007). Online auction and list price revenue management. Management Science, 53, 795-813.

Etzion, H., Pinker, E., \& Seidmann, A. (2006). Analyzing the simultaneous use of auctions and posted prices for online selling. Manufacturing \& Service Operations Management, 8, 68-91.

Gneezy, U., \& Smorodinsky, R. (2006). All-pay auctions - An experimental study. Journal of Economic Behavior and Organization, 61, 255-275.

R. Guina, (2009). Swoopo - Legitimate Auction Deals or a Scam?, blog 2009-06-04. $<$ http://cashmoneylife.com/swoopo-review-auction-deals-or-scam/> (Accessed 09.05.14).

Haruvy, E., Popkowski Leszczyc, P., Carare, O., Cox, J., Greenleaf, E., Jank, W., et al. (2008). Competition between auctions. Marketing Letters, 19, 431-448.

Hinnosaar, T. (2013). Penny Auctions are Unpredictable, working paper. <http:// toomas.hinnosaar.net/pennyauctions.pdf> (Accessed 09.05.14).

Krishna, V. (2002). Auction theory. Orlando, Florida: Academic Press.

Krishna, V., \& Morgan, J. (1997). An analysis of the war of attrition and the all-pay auction. Journal of Economic Theory, 72, 343-362.

Maynard Smith, J. (1974). The theory of games and the evolution of animal conflicts. Journal of Theoretical Biology, 47, 209-221.

Milgrom, P., \& Weber, R. (1985). Distributional strategies for games with incomplete information. Mathematics of Operations Research, 10, 619-632.

Myerson, R. (1981). Optimal auction design. Mathematics of Operations Research, 6, 58-73.

Myerson, R. (1991). Game theory. Cambridge, Massachusetts: Harvard University Press.

NY Times, (2009a). Sites Ask Users to Spend to Save, article 2009-08-17. <http:// www.nytimes.com/2009/08/17/technology/internet/17shop.html> (Accessed 09.05.14).

NY Times, (2009b). Paying a Price for the Thrill of the Hunt, article 2009-11-15. <http://www.nytimes.com/2009/11/15/business/economy/15view.html> (Accessed 09.05.14).

O'Neil, B. (1986). International escalation and the dollar auction. Journal of Conflict 
Resolution, 30, 33-50.

Oswold, E. (2011). Swoopo quietly files for bankruptcy. blog 2011.03.25. <http:// technologizer.com/2011/03/25/swoopo-quietly-files-for-bankruptcy/> (Accessed 09.05.14).

Pinker, E., Seidmann, A., \& Vakrat, Y. (2003). Managing online auctions: Current business and research issues. Management Science, 49, 1457-1484.

Platt, B., Price, J., \& Tappen, H. (2013). The role of risk preferences in pay-to-bid auctions. Management Science, 59(9), 2117-2134.

Riley, J., \& Samuelson, W. (1981). Optimal auctions. American Economic Review, 71, 391-392.

Robinson, S., Giebelhausen, M., \& Cotte, J. (2013). Shopping, gambling or shambling? An introduction to penny auctions. Journal of Business Research, 66, 1612-1616.

Rothkopf, M., \& Harstad, R. (1994). Modeling competitive bidding: A critical essay. Management Science, 40, 364-384.

Shen, Z., \& Su, X. (2007). Customer behavior modeling in revenue management and auctions: A review and new research opportunities. Production and Operations Management, 16, 713-728.

Swider, D., \& Weber, C. (2007). Bidding under price uncertainty in multi-unit payasbid procurement auctions for power systems reserve. European Journal of Operational Research, 181, 1297-1308.

USA Today, (2011). Don't gamble on penny auction sites, article 201-05-13. <http:// www.usatoday.com/tech/columnist/kimkomando/2011-05-13-komando-pennyauctions_ n.htm> (Accessed 09.05.14).

Vickrey, W. (1961). Counterspeculation, auctions, and competitive sealed tenders.

The Journal of Finance, 16, 8-37. 